\title{
Cardiometabolic Comorbidities in Patients With Psoriasis: Focusing on Risk, Biological Therapy, and Pathogenesis
}

\author{
Jiangluyi Cai ${ }^{1,2 \dagger}$, Lian Cui ${ }^{2,3 \dagger}$, Yu Wang ${ }^{1,2 \dagger}$, Ying $\mathrm{Li}^{1,2}$, Xilin Zhang ${ }^{1,2 *}$ and Yuling Shi ${ }^{1,2 *}$ \\ ${ }^{1}$ Department of Dermatology, Shanghai Skin Disease Hospital, Tongji University School of Medicine, Shanghai, China, ${ }^{2}$ Institute of \\ Psoriasis, Tongji University School of Medicine, Shanghai, China, ${ }^{3}$ Department of Dermatology, Shanghai Tenth People's \\ Hospital, Tongji University School of Medicine, Shanghai, China
}

\section{OPEN ACCESS}

Edited by: Anna Lisa Giuliani, University of Ferrara, Italy

Reviewed by:

Mark Lebwohl,

Icahn School of Medicine at Mount

Sinai, United States

Eva Reali,

University of Milano-Bicocca, Italy

*Correspondence: Yuling Shi

shiyuling1973@tongji.edu.cn

Xilin Zhang

xilin206@163.com

${ }^{t}$ These authors have contributed equally to this work

Specialty section:

This article was submitted to Inflammation Pharmacology,

a section of the journal

Frontiers in Pharmacology

Received: 13 September 2021

Accepted: 14 October 2021

Published: 04 November 2021

Citation:

Cai J, Cui L, Wang Y, Li Y, Zhang Xand Shi Y (2021) Cardiometabolic Comorbidities in Patients With

Psoriasis: Focusing on Risk, Biological

Therapy, and Pathogenesis.

Front. Pharmacol. 12:774808.

doi: 10.3389/fphar.2021.774808
Psoriasis is a chronic inflammatory disease characterized by erythematous scaly plaques, accompanied by systemic damage that leads to the development of multiple comorbidities. In particular, the association between psoriasis and cardiometabolic comorbidities, including cardiovascular diseases (CVDs), obesity, diabetes mellitus, and metabolic syndrome, has been verified in a considerable number of clinical trials. Moreover, the increased risk of cardiometabolic comorbidities positively correlates with psoriasis severity. Biologic therapy targeting inflammatory pathways or cytokines substantially improves the life quality of psoriasis patients and may affect cardiometabolic comorbidities by reducing their incidences. In this review, we focus on exploring the association between cardiometabolic comorbidities and psoriasis, and emphasize the benefits and precautions of biologic therapy in the management of psoriasis with cardiometabolic comorbidities. The pathogenic mechanisms of cardiometabolic comorbidities in psoriasis patients involve common genetic factors, lipid metabolism, insulin resistance, and shared inflammatory pathways such as tumor necrosis factor- $\alpha$ and interleukin-23/Th-17 pathways.

Keywords: psoriasis, biologics, cardiovascular disease, diabetes mellitus, obesity, metabolic syndrome

\section{INTRODUCTION}

Psoriasis is a chronic immune-mediated inflammatory disease characterized by erythematous scaly plaques that commonly develop on extensor surfaces. Its histopathological features are hyperkeratosis, parakeratosis, epidermal acanthosis, and the infiltration of immune cells. Psoriasis has been estimated to affect $2-3 \%$ of the world population and has deleterious effects on the quality of life of patients (Griffiths and Barker, 2007).

With recent advances in the understanding of psoriasis, the disease is increasingly being considered as a systemic inflammatory disorder rather than only involving the skin and joints. An increased risk of inflammatory comorbidities such as cardiovascular diseases (CVDs) and metabolic diseases, collectively called cardiometabolic comorbidities, has been reported in psoriasis patients. There is increasing awareness that cardiovascular risk factors would enhance the potential risks of cardiovascular morbidity and mortality in affected psoriasis patients (Neimann et al., 2006). Psoriasis is also typically related to metabolic diseases including obesity, diabetes mellitus, and metabolic syndrome, which manifests as a combination of central obesity, hypertension, insulin 
resistance, and dyslipidemia (Johnsson et al., 2012). The incidences of major adverse cardiovascular events (MACEs), a composite endpoint comprised of myocardial infarction, cerebrovascular accident, and cardiovascular death, have been reported to be higher in patients with severe psoriasis (Abuabara et al., 2010; Mehta et al., 2010; Ahlehoff et al., 2012). Indeed, with an increase in the severity of psoriasis, patients are prone to a higher risk of CVDs, suggesting that the prevalence of cardiovascular events positively correlates with psoriasis severity. Analogous positive trends have also been identified between metabolic disorders and psoriasis independent of obesity and other risk factors (Yeung et al., 2013).

There has been a continuous innovation in the management of psoriasis along with the advances in understanding of its pathogenic mechanisms and essential inflammatory pathways (Boehncke and Schön, 2015). Targeted immunotherapy, including the agonists of tumor necrosis factor- $\alpha$ (TNF- $\alpha$ ), interleukin-(IL)-17 and IL-23, has achieved great success (Mahil et al., 2016). First-generation biologics involves a group of TNF- $\alpha$ inhibitors, including monoclonal antibodies adalimumab, infliximab, certolizumab-pegol, and golimumab as well as its fusion protein etanercept. Second-generation biologics are composed of IL-12/23 and IL-17 inhibitor family: anti-IL12/23p40 antibody ustekinumab; anti-IL-23p19 antibodies guselkumab, risankizumab, and tildrakizumab; anti-IL-17A antibodies secukinumab and ixekizumab; and anti-IL-17 receptor a antibody brodalumab (Rønholt and Iversen, 2017). They have now become prevalent regimens for the induction and maintenance of curative effect in patients with severe psoriasis that a higher proportion of patients have achieved Psoriasis Area Severity Index 75 (PASI 75) and PASI 90 after long-time treatment (Papp et al., 2005; Reich et al., 2005; Saurat et al., 2008). Their rapid efficacy has greatly improved the life quality of psoriasis patients (Rønholt and Iversen, 2017).

Because of the frequent association between psoriasis and cardiometabolic disorders, the impact of psoriasis therapy on the risk of cardiometabolic comorbidities have aroused our attention. In the clinical trials aimed at investigating the efficacy and safety profile of biologic therapies for psoriasis, the number of MACE cases was generally higher in the biologic groups than in the placebo groups. However, the intergroup difference was not statistically significant. This prompted us to recognize the cardiovascular risk during the medication of biologics in psoriasis patients (D'Adamio et al., 2019). TNF- $\alpha$ inhibitors reduce the risk of cardiovascular events and improve the cardiovascular outcome in patients with psoriasis, (Lee et al., 2019a). IL-17A, another important biologic target of psoriasis, plays a vital role in the pathogenesis of both psoriasis, and atherosclerotic plaques that accumulating evidence supports a beneficial influence of its agonists on related cardiometabolic comorbidities (Roubille et al., 2015; Lockshin et al., 2018). On the other hand, cardiometabolic comorbidities also affect the therapeutic effects of biologics (Boyd and Kavanaugh, 2015). Therefore, the impact of biologic therapies on cardiometabolic comorbidities should not be ignored during the treatment of psoriasis.

In this review, we explored the association between biologics and cardiometabolic comorbidities in patients with psoriasis to determine optimal systemic management of psoriasis by early screening and intervention for cardiometabolic comorbidities. We discuss the overlapping mechanisms between psoriasis and associated cardiometabolic comorbidities, especially the shared inflammatory pathways between psoriasis and cardiometabolic diseases linked to a sequence of inflammatory cascade reactions driven by increased T helper 1 (Th1), Th17 lymphocytes and associated proinflammatory cytokines, including TNF- $\alpha$, IL- $1 \beta$, IL-17 and IL-23 (Davidovici et al., 2010). Other overlapping pathogenic mechanisms between psoriasis and comorbid cardiometabolic disorders have been proposed to be caused by common genetic factors (Lu et al., 2013), secretion of adipokines (Deng and Scherer, 2010; Robati et al., 2014), lipoprotein particles (Salahuddin et al., 2015), insulin resistance (Gyldenløve et al., 2015), angiogenesis (Malecic and Young, 2017), endothelial dysfunction (Karbach et al., 2014), and oxidative stress (Armstrong et al., 2011; Lockshin et al., 2018).

\section{MANUSCRIPT FORMATTING}

\section{Risk of Cardiometabolic Diseases in Psoriasis \\ Psoriasis and Cardiovascular Diseases}

The increased risk of MACEs in patients with psoriasis has been discussed for decades. Previous studies showed a markedly increased incidence of cardiovascular diseases among psoriasis patients (Miller et al., 2013). A prominent role of chronic inflammation in CVDs was firstly noted (Ridker et al., 1997). Subsequently, a prospective population-based cohort study in the United Kingdom discovered that there existed a higher cardiovascular risk in patients with systemic chronic inflammatory conditions including psoriasis (Gelfand et al., 2006; Ridker, 2010). The study prompted the process of defining the association between psoriasis and cardiovascular events. Gelfand et al reported that psoriasis was an independent risk factor for myocardial infarction (MI), especially in young individuals with severe psoriasis (Gelfand et al., 2006). Furthermore, a cohort study using the General Practice Research Database demonstrated that patients with severe psoriasis are at a higher risk of cardiovascular mortality after controlling for major cardiovascular risk factors, providing stronger evidence that severe psoriasis may be an independent risk factor for cardiovascular death (Mehta et al., 2010). However, the higher prevalence of conventional cardiovascular risk factors, which are comprised of smoking, diabetes, lipid abnormalities, and hypertension, in psoriasis patients has been confirmed in many observational studies (Stern, 2010). It is well-established that psoriasis increases the risk of MI and ischemic stroke, and more recent studies have linked psoriasis with an increased risk of other CVDs such as heart failure and atrial fibrillation (Ahlehoff et al., 2012; Khalid et al., 2014). The risk of cardiovascular events is also linked to a positive dose-response relationship with 
objectively-measured psoriasis severity and cumulative duration of psoriasis (Yeung et al., 2013; Egeberg et al., 2017).

\section{Psoriasis and Obesity}

For a long time, obesity has been considered as a cardiovascular risk factor along with other factors including smoking, hypertension, and hyperlipidemia. It has been shown to be more prevalent in psoriasis patients than in patients without psoriasis (Shapiro et al., 2012). The relationship between obesity and psoriasis is estimated to be interrelated that obesity correlates with an increased risk of psoriasis and psoriasis might conversely lead to the occurrence of obesity (Budu-Aggrey et al., 2019). A recent meta-analysis of prospective studies showed that the relative risk of the relevance between psoriasis risk and per 5unit increment in body mass index (BMI), per 10-cm increment in waist circumference, per 0.1-unit increment in the waist-to-hip ratio, per $5 \mathrm{~kg}$ of weight gain was 1.19 (95\% CI: 1.10-1.28), 1.24 (95\% CI: 1.17-1.31), 1.37 (95\% CI: 1.23-1.53), and 1.11 (95\% CI: 1.07-1.16), respectively, concluding that risk of psoriasis increases with the degree of obesity measured by the four abovementioned aspects (Aune et al., 2018). As the severity of psoriasis has a positive correlation with weight gain, several studies investigated the impact of weight loss on psoriasis severity through low-energy diet or bariatric surgery (Jensen et al., 2013; Shelling and Kirsner, 2013; Debbaneh et al., 2014). They found that weight loss in overweight patients with psoriasis showed a declined trend of psoriasis severity manifested as a reduction of PASI and improved quality of life (Jensen et al., 2013; Shelling and Kirsner, 2013; Debbaneh et al., 2014). It is possible that psoriasis might develop first and bring about obesity. This view is supported by the substantial lipid abnormalities in psoriasis patients and the increased incidence of adiposity, especially central adiposity, following the development of psoriasis in children (Mallbris et al., 2006; Paller et al., 2013).

\section{Psoriasis and Diabetes Mellitus}

Diabetes mellitus, considered as one of the traditional cardiovascular-related risk factors that can contribute to cardiovascular morbidity and mortality, has been linked to psoriasis in many clinical trials and meta-analyses (Miller et al., 2013). In a Danish nationwide cohort study, the incidence rate of new-onset diabetes mellitus increased among patients with psoriasis compared with the population without psoriasis and was positively correlated with psoriasis severity after correcting for confounding factors such as age, sex, concomitant medication, comorbidity, and socioeconomic status (Khalid et al., 2013). This phenomenon was also identified in a meta-analysis of 44 observational studies that showed a higher risk of type 2 diabetes mellitus (T2DM) [odds ratio (OR): 2.10, 95\% CI: 1.73-2.55] in patients with severe psoriasis (Wu et al., 2015). In addition to diabetes mellitus itself, its related systemic complications also show a positive relationship with moderateto-severe psoriasis, the severity of which was objectively measured by the body surface area (BSA) affected, independently of other risk factors including obesity and smoking (Yeung et al., 2013). The risk of psoriasis development is higher in diabetes patients, which is associated with drug exposure in those treated with anti-diabetic therapies. An increasing risk of psoriasis is linked to the frequent use of insulin (adjusted OR: 1.29, 95\% CI: 1.18-1.42, $p<0.001$ ). On the other hand, a reduction in the risk of psoriasis is related to the frequent use of thiazolidinedione (TZD) (adjusted OR: 0.89, 95\% CI: 0.81-0.98) compared with low-frequency TZD users (Wu et al., 2015). Conversely, concomitant medication during the treatment of psoriasis could also modulate the risk of T2DM incidence (Lee et al., 2014).

A Danish population-based twin study revealed that genetic and environmental factors play a role in the comorbidity of psoriasis and T2DM (Lønnberg et al., 2016). Pleiotropic susceptibility loci CDKAL1 contributes to the occurrence of psoriasis as well as diabetes mellitus (Wolf et al., 2008), which may upregulate inflammatory cytokines in psoriasis and thus promote insulin resistance, an independent risk factor of T2DM (Gelfand, 2016). A study indicated that insulin resistance or impaired insulin sensitivity exists in psoriasis patients with normal glucose tolerance, which may further result in the development of diabetes mellitus (Gyldenløve et al., 2015). Systemic inflammation may be a potential shared pathophysiologic pathway between psoriasis and diabetes mellitus. Inflammatory mediators such as TNF- $\alpha$, IL-6, leptin, and adiponectin affect the regulation of insulin sensitivity by various interactions via signaling pathways between insulin receptors and cytokines or adipocytokines (Davidovici et al., 2010; Donath, 2014).

\section{Psoriasis and Metabolic Syndrome}

Metabolic syndrome is a comprehensive term for a cluster of interrelated metabolic disorders such as abdominal obesity, hypertension, insulin resistance, dysglycemia, and dyslipidemia (Eckel et al., 2010). It is associated with higher risks of cardiometabolic diseases, including coronary artery diseases and type 2 diabetes mellitus, and all-cause mortality (Gami et al., 2007). An increased prevalence of metabolic syndrome was confirmed in patients with psoriasis compared with general population in a meta-analysis of 12 observational studies (pooled OR: 2.26, 95\% CI: 1.70-3.01) (Armstrong et al., 2013). A subsequent meta-analysis reached a similar conclusion after adjusting for confounders (pooled OR: 1.42, 95\% CI: 1.28-1.65) (Rodríguez-Zúñiga and García-Perdomo, 2017), and showed that the risk of metabolic syndrome was closely related to psoriasis severity (Parodi et al., 2014). Dyslipidemia and hypertension are considered essential components of metabolic syndrome and had a higher prevalence among patients with psoriasis than in control groups in previous research (Kim et al., 2019; Snekvik et al., 2019). The potential risk of triggering psoriasis among patients with metabolic syndrome was found to increase in a prospective study; the association between individual components of metabolic syndrome and the incidence of psoriasis was also explored in this study (Kim et al., 2019). Some individual components such as a low level of high-density lipoprotein (HDL) cholesterol, a high level of triglycerides, and abdominal obesity promote psoriasis 
development (Snekvik et al., 2019). However, the conclusion about the impact of elevated blood pressure and fasting plasma glucose levels on the incidence of psoriasis remains controversial (Wu et al., 2014; Kim et al., 2017; Kim et al., 2019). Hence, more research is needed to determine the association between these factors.

\section{Effect of Tumor Necrosis Factor- $\alpha$ Inhibitors on Cardiometabolic Outcomes in Psoriasis Effect on Cardiovascular Diseases}

Psoriasis accompanied by the occurrence of high-risk cardiovascular events is associated with the spread of inflammation through blood vessels by the interactions of cytokines. Various studies have demonstrated that the risk of cardiovascular comorbidities in psoriasis patients reduced after treatment with TNF- $\alpha$ inhibitors. TNF- $\alpha$ has been identified as a pivotal cytokine in the pathogenesis of both atherosclerosis and autoimmune diseases such as rheumatoid arthritis (RA) and psoriasis (McKellar et al., 2009). Treatment with TNF- $\alpha$ inhibitors in psoriasis patients could reverse early atherosclerosis at the initial stage presented as significantly reduced arterial intima-media thickness (IMT) values without irreversible atherosclerotic plaque (which indicates the development of subclinical atherosclerosis) and decreased signal intensity on $\beta$-2-(18F)-fluoro-2-deoxy-D-glucosePositron emission tomography/computed tomography (FDGPET/CT), implying less vascular inflammation (Jókai et al., 2013; Dey et al., 2017). However, a randomized controlled trial (RCT) showed that the target-to-background ratio (TBR) of carotid vessel walls, an indicator of vascular inflammation, had a modest increase after adalimumab treatment for 52 weeks (Bissonnette et al., 2017). Anti-TNF- $\alpha$ therapy also has a favorable effect on the improvement of arterial stiffness, measured by the gold standard aortic pulse wave velocity $(\mathrm{aPWV})$, in patients with psoriatic arthritis (Angel et al., 2010). Despite that a recent systematic review showed no significant effect of TNF- $\alpha$ inhibitors on the subclinical indicators of atherosclerosis in inflammatory diseases including psoriasis, a positive effect of TNF- $\alpha$ biologics on the clinical outcomes of CVDs via alternate pathways, such as primary disease remission or reduced prothrombotic tendency, cannot be ruled out (Knowles et al., 2020).

The cardioprotective effect of TNF- $\alpha$ inhibitors that reduce the risk of MI compared with topical agents has been demonstrated in a retrospective cohort study (Wu and Poon, 2013a; Wu and Poon, 2013b). Coronary microvascular dysfunction as a result of systematic inflammation in psoriasis patients was ameliorated manifested as an increase in the coronary flow reserve (CFR) from $2.2 \pm 0.7$ to $3.02 \pm 0.8(p<0.0001)$ after anti-TNF- $\alpha$ therapy (Piaserico et al., 2016). Psoriasis patients receiving biologic agents including TNF- $\alpha$ inhibitors showed almost no difference in the progression of asymptomatic coronary artery diseases (CAD) in a follow up, while CT imaging data suggested a significant increase in the procession of CAD in the control group (Herédi et al., 2016). Another study confirmed a decreased burden of noncalcified coronary plaques after anti-TNF- $\alpha$ therapy compared with the patients who did not receive biologic treatment $(p<0.01)$ (Elnabawi et al., 2019a). Clinical or subclinical cardiac dysfunction such as left ventricular diastolic dysfunction and right ventricular systolic dysfunction is slightly more prevalent in patients with psoriasis, which has been uncovered to be ameliorated upon TNF- $\alpha$ inhibitor therapy (Ahlehoff et al., 2016; Herédi et al., 2016).

Whether the risk of heart failure reduces or increases in psoriasis patients treated with TNF- $\alpha$ inhibitors has been discussed for a long time. It has been reported that TNF- $\alpha$ has detrimental effects on chronic heart failure (CHF). However, there is no conclusive evidence to prove the specific therapeutic effect of TNF- $\alpha$ inhibitors on CHF in psoriasis patients (Hori and Yamaguchi, 2013). Multiple clinical trials have demonstrated that etanercept does not affect hospitalization or mortality due to CHF (Mann et al., 2004; Campanati et al., 2020). A high dose of infliximab exacerbates the CHF condition in psoriasis patients with CHF (Chung et al., 2003). The dose-dependent association between the deterioration of CHF and the application of TNF- $\alpha$ inhibitors has prompted the cautious usage of this agent in patients with CHF (Campanati et al., 2020). The New York Heart Association recommends that TNF- $\alpha$ inhibitors are contraindicated in patients with class 3 or 4 CHF as well as those with class 1 or $2 \mathrm{CHF}$ whose ejection fraction is lower than 50\% (Menter et al., 2008).

Psoriasis patients with cumulative exposure to TNF- $\alpha$ inhibitors for 6 months had more than $11.2 \%$ reduction of cardiovascular event risk compared with those who received phototherapy [hazard ratio (HR): $0.89,95 \%$ confidence interval (CI): $0.79-0.99, p=0.048]$ in a large-scale observational cohort study (Wu et al., 2018). A similar conclusion was reached in another study that the risk of cardiovascular events in patients receiving TNF- $\alpha$ inhibitors was lower than those receiving methotrexate (Wu J. J. et al., 2017). A meta-analysis of five studies including 49,795 patients with plaque psoriasis or psoriatic arthritis also verified the efficacy of anti-TNF- $\alpha$ therapy in decreasing the incidence of cardiovascular events (Yang et al., 2016). Another metaanalysis of 38 RCTs involving 18,024 patients treated with biologic therapy including TNF- $\alpha$ inhibitors reported 10 cases of MACEs in nine RCTs. However, a pooled analysis showed no significant statistical difference in the incidence of MACEs in patients treated with biologic therapy compared with those treated with conventional therapy or placebo (OR: 1.45, 95\% CI: 0.34-6.24) (Rungapiromnan et al., 2017). Therefore, more RCTs are needed to provide the basis for the selection and rational usage of biologic agents in order to minimize the cardiovascular risk in patients with psoriasis (Gelfand, 2018).

\section{Effects on Cardiovascular Biomarkers}

The risk of CVDs, including coronary heart diseases and peripheral arterial diseases, can be predicted and characterized by cardiovascular biomarkers such as C-reactive protein (CRP) and vascular endothelial growth factor, which are related to systemic inflammation and endothelial dysfunction (Heeschen et al., 2003; Melander et al., 2009). The serum levels of these factors decreased after TNF- $\alpha$ inhibitor therapy for over 24 weeks 
in a prospective study (Boehncke et al., 2011). Another study investigated six additional cardiovascular risk markers, including vascular cell adhesion molecule-1 (VCAM-1), intercellular adhesion molecule-1, E-selectin, matrix metalloproteinase-9, myeloperoxidase, and total plasminogen activator inhibitor-1. They are linked to BMI and waist-hip ratio, and participate in the onset and development of cardiometabolic diseases, especially metabolic syndrome, in psoriasis patients (Sigurdardottir et al., 2014).

\section{Effects on Metabolic Disorders}

An association between weight gain and TNF- $\alpha$ inhibitor has been reported. And, different types of TNF- $\alpha$ inhibitors were associated with distinct characteristics of weight gain among the patients (Saraceno et al., 2008). The efficacy and response of TNF- $\alpha$ inhibitors with fixed-dose medications such as etanercept are impaired in obese individuals (Clark and Lebwohl, 2008). Furthermore, the results from a prospective study suggested that successful weight loss ( $\geq 5 \%$ from baseline values) by concomitant dietary intervention in obese patients resulted in a higher rate of disease improvement defined as minimal disease activity in patients with psoriatic arthritis (Di Minno et al., 2014). Therefore, in order to treat psoriasis and associated obesity, appropriate diet, physical exercise as well as weight loss are necessary to improve the therapeutic effect of biologic agents (Dalamaga and Papadavid, 2019). The clinical response to infliximab or ustekinumab is not affected by body weight in the treatment of psoriasis patients, because they are dosed in a weight-based manner (Clark and Lebwohl, 2008; Dalamaga and Papadavid, 2019).

A retrospective cohort study among RA and psoriasis patients revealed a decreased risk of diabetes mellitus among patients treated with TNF- $\alpha$ inhibitors compared with those treated with other nonbiologic agents (Solomon et al., 2011). Studies concerning the effects of etanercept on insulin sensitivity, which is a pivotal factor during the onset of metabolic syndrome and diabetes mellitus, show that etanercept has a positive effect on improving fasting glucose levels by attenuating insulin resistance (Marra et al., 2007; Stanley et al., 2011). Contradictory results have been reported in a RCT that the application of etanercept failed to change insulin secretion and sensitivity in psoriatic patients (Martínez-Abundis et al., 2007). Insulin sensitivity has been improved by another TNF- $\alpha$ inhibitor adalimumab in psoriasis patients without diabetes (Pina et al., 2015).

There is evidence that TNF- $\alpha$ inhibitors may have favorable effects on certain conditions of metabolic syndrome in the management of psoriasis. However, further exploration is needed to more precisely determine the influence (Channual et al., 2009). The impact of anti-TNF- $\alpha$ treatment on the lipid profile of psoriasis patients has not been concluded so far. Recently, a prospective cohort study reported that TNF- $\alpha$ inhibitors are beneficial for regulating the metabolic state by decreasing the levels of total cholesterol and low-density lipoprotein cholesterol (Botelho et al., 2020), but no significant difference occurred after adalimumab treatment in another study (Bissonnette et al., 2013).

\section{Effect of IL-12/23 Inhibitors on Cardiometabolic Outcomes in Psoriasis}

Biologics targeting IL-23 include two types of monoclonal antibodies, namely anti-IL-12/23p40, including ustekinumab, briakinumab, and anti-IL-23p19, including guselkumab, tildrakizumab, and risankizumab. Multiple RCTs and pooled analyses have proven the safety of IL12/23p40 inhibitors; however, one of the anti-IL-12/23 compounds, briakinumab, was withdrawn from the market due to an increased cardiovascular risk since it caused frequent MACEs in the early phase (Gordon et al., 2012; Langley et al., 2013).

\section{Clinical Evidence for the IL-12/23p40 Inhibitor Ustekinumab}

The safety profile of another IL-12/23 inhibitor ustekinumab aroused concern after the withdrawal of briakinumab due to the high incidence of MACEs, and further studies aimed to evaluate the cardiovascular risk of this class of compounds. During a 3years follow-up study, the combined MACE rate per 100 patientyears was 0.44 (95\% CI: $0.27-0.67)$ in a pooled analysis of phase II/III clinical studies of ustekinumab on moderate-to-severe psoriasis, and the comparison of the standardized incidence ratios of psoriasis patients treated with ustekinumab with general population suggests that the effect of ustekinumab on MACEs is neither detrimental nor beneficial (Reich et al., 2011). A meta-analysis of 22 RCTs involving 10,183 psoriasis patients also showed no significant difference in the MACE rate between patients receiving anti-IL-12/IL-23 and placebo, with a MantelHaenszel risk difference of 0.012 events/person-year (95\% CI: -0.001 to $0.026 ; p=0.12$ ) (Ryan et al., 2011), but a higher risk of MACEs in patients receiving IL-12/23 antibodies in comparison with placebo was found after the evaluation of the same trials using another statistical technique named the Peto OR method (Tzellos et al., 2013). The increased rate of MACEs in patients treated with anti-IL-23 therapy was confirmed in a meta-analysis of randomized clinical trials that mainly covered individuals with high cardiovascular risk (Ait-Oufella et al., 2019). A recent casetime-control study also identified a significant association between the initiation of treatment with ustekinumab and the early occurrence of severe cardiovascular events (OR: 4.17; 95\% CI: 1.19-14.59) (Choi et al., 2020). Data from the PHOENIX 1 study of long-term ustekinumab treatment in patients with an extended duration of exposure showed a favorable safety profile and stable clinical response (Kimball et al., 2013). The influence of IL-12/23 inhibitors on cardiovascular safety was also compared with those of other biologics approved for the treatment of psoriasis in some trials, which reported a comparable risk of MACEs among ustekinumab, TNF- $\alpha$ inhibitors, and IL-17 inhibitors (Kimball et al., 2013; Ikonomidis et al., 2017; Gelfand, 2018). The risk of atrial fibrillation and MACEs did not substantially differ between treatment initiated with ustekinumab and TNF- $\alpha$ inhibitors in a cohort study (Lee et al., 2019a). However, in another analysis, ustekinumab showed a greater improvement in vascular, coronary and myocardial function, which was reflected in improved global longitudinal strain, left ventricular twisting, percent difference 
between peak twisting and untwisting at mitral valve opening (\% untwMVO), and CFR as well as reduced circulating N-terminal pro-B-type natriuretic peptide (NT-proBNP) levels (Ikonomidis et al., 2017). To investigate the effect of biological therapy on the characteristics of coronary plaque phenotypes that partly determine the risk of MI, 290 participants treated with biologics were included in a 1-year follow-up study performed with serial coronary computed tomography angiography and the collection of clinical and laboratory data, and an improvement in the high-sensitivity-c-reactive protein (hs-CRP) level and a reduction in the non-calcified plaque burden were observed in the anti-IL-12/23 treatment group, which was inferior to the effects of anti-TNF- $\alpha$ and anti-IL-17 in the prospective, observational study (Hjuler et al., 2016). The incidence of a lipid-rich necrotic core, which is a high-risk coronary plaque feature, was also found to decrease after 1 year of biological therapy, including anti-TNF- $\alpha$, anti-IL-12/23, and anti-IL-17 therapy, compared with the nonbiologic therapy group (Poizeau et al., 2020). Similarly, anti-IL-12/23 and anti-IL-17 therapy was associated with a significant reduction in coronary inflammation measured by the perivascular fat attenuation index in a prospective cohort study (Hjuler et al., 2016).

Although anti-TNF- $\alpha$ therapy appears to increase the weight and BMI of patients, this effect does not appear in patients treated with anti-IL-12/23 therapy with weight-adjusted doses, suggesting that ustekinumab could be considered to treat overweight and obese patients with psoriasis (Wu et al., 2020). However, the significance of weight loss during the biological treatment of obese patients cannot be ignored because multiple studies have proven that a reduction in weight improves the clinical response to ustekinumab (Zhu et al., 2009; Gisondi et al., 2016). No significant change in the mean lipid levels after the biological therapy, including ustekinumab or placebo, for 1 year at follow-up was observed in another study (Hjuler et al., 2016). Similar results were also observed for BMI, lipid and glucose levels, which remained unchanged at the 1-year follow-up assessment of psoriasis patients treated with biologics (Elnabawi et al., 2019b).

\section{Ongoing Research About IL-23p19 Inhibitors}

Agents targeting the p19 subunit of the IL-23 cytokine pathway have been approved for treatment only for 3 years, so the data for the incidence of MACEs in the clinical trials for the safety profile of IL-23p19 inhibitors is not sufficient to determine its influence on the cardiovascular risk of psoriasis patients (Blauvelt et al., 2017; Papp et al., 2017). Three completed phase 3 trials of guselkumab in the treatment of psoriasis, including VOYAGE 1 (NCT02207231), VOYAGE 2 (NCT02207244), and NAVIGATE (NCT02203032) reported low rates $(<1.5 \%)$ of MACE occurrence over the study period in all groups (Blauvelt et al., 2017; Reich et al., 2017; Langley et al., 2018). A pooled analysis of three RCTs on tildrakizumab, including a phase 2b study (NCT01225731) and reSURFACE 1 (NCT01722331) and 2 (NCT01729754), also reported low rates of MACEs (Blauvelt et al., 2018). A low incidence of MACE was also reported in two phase 3 trials of risankizumab vs ustekinumab: UltIMMa-1 (NCT02684370) and UltIMMa-2 (NCT02684357) (Gordon et al., 2018). A total of 109 studies on the efficacy and safety of the therapy for psoriasis involving biologic agents were included in a network meta-analysis suggesting that no significant difference exists in the risk of MACE occurrence among guselkumab, tildrakizumab, ustekinumab, certolizumab, infliximab, adalimumab, and etanercept, versus placebo (Sbidian et al., 2017). More data are needed to confirm the effect of the anti-IL-23p19 agents on cardiovascular and metabolic risk.

\section{Relationship Between IL-17 Inhibitors and Cardiovascular Risk in Psoriasis IL-17 and Atherosclerosis}

The existing data evaluating the effects of IL-17 inhibitors as newly-approved clinical biologic agents targeting IL-17 signaling on the risk of CVDs in psoriasis patients are insufficient. However, experimental data have shown that overexpression of IL-17A in keratinocytes of the murine model [K14-IL-17A (ind/+)] induced systemic vascular inflammation, arterial hypertension, and endothelial dysfunction, all of which can lead to an increased risk of CVDs (Karbach et al., 2014). IL$17 \mathrm{~A}$, which is involved in the development of psoriasis, is also implicated in the pathogenesis of CVDs, which suggests that IL17A-mediated inflammation may become a potential overlapping pathological mechanism between psoriasis and its cardiovascular comorbidities (Lockshin et al., 2018). Research on atherosclerosis yielded conflicting results, suggesting that the IL-17 mainly produced by Th17 cells may promote or prevent atherosclerotic plaque development and stability, which are determined by specific inflammatory condition (Taleb et al., 2015). Atherosclerotic plaque stability is enhanced by the cytokine profile of increased IL-17 levels and decreased level of interferon- $\gamma$ (IFN- $\gamma$ ) in the local microenvironment, whereas the increased production of IL-17 and IFN- $\gamma$ has a synergistic pro-inflammatory effect in promoting disease progression (Taleb et al., 2015). Other studies also suggested that IL-17 maintained the stability of atherosclerotic plaques by promoting the generation of collagen and smooth muscle cells and downregulating the level of VCAM-1 (Taleb et al., 2009; Gistera et al., 2013). However, the findings regarding the percentage of circulating Th17 cells and related cytokine IL$17 \mathrm{~A}$ in patients with acute coronary syndromes are discordant that some reported increasing levels and others showed no significant difference in comparison with patients without coronary artery diseases (Cheng et al., 2008; Eid et al., 2009). The association between IL-17-mediated inflammation and atherosclerotic plaque conformation as well as the instability has yielded evidence for the hypothesis that psoriasis patients have a high risk of MI (Chen et al., 2010). Given the association between IL-17 and atherosclerosis in psoriasis, the effects of IL-17 inhibitors on cardiovascular comorbidities in the treatment of psoriasis should be evaluated carefully.

\section{IL-17 Inhibitors and Cardiovascular Events}

In phase III clinical trial programs of IL-17 inhibitors, a small section of patients experienced a few cases of MACEs (Langley 
et al., 2014; Griffiths et al., 2015; Lebwohl et al., 2015). Low levels of IL-17 in patients has been shown to be associated with a higher risk of recurrent MI and death in the related research (Simon et al., 2013). In a meta-analysis including 5,951 patients from 9 RCTs that compared the efficacy and safety of IL-17 inhibitors with placebo, six cases of MACEs were reported in 2,143 patients treated with IL-17 inhibitors whereas 700 patients treated with placebo reported only one MACE across four studies; however, no significant difference was observed between IL-17 inhibitors and placebo (Wu D. et al., 2017). Another meta-analysis of the effect of biologic therapy on the risk of MACEs showed 2 MACEs in 514 patients receiving IL-17 inhibitors among 8 MACEs in patients treated with various biologics $(n=12,596)$ and 2 MACEs in the placebo group $(n=5,092)$, and the pooled analysis of biologics and placebo, as well as various separate agents including TNF- $\alpha$ inhibitors, anti-IL-17A agents, or anti-IL-12/23 agents, did not show a significant difference in the risk of MACEs (Rungapiromnan et al., 2017). In a prospective, observational study of 215 psoriasis patients receiving biologic therapy recruited over a 1-year follow-up, an improvement in hs-CRP and HDL cholesterol level was observed in the anti-IL17-treated groups, and the most significant reduction (up to 12\%) in coronary plaque burden appeared in the anti-IL-17 therapy group among all biologic-treated groups (Elnabawi et al., 2019a). Exposure-adjusted incidence rates of cardiovascular events were comparable between the secukinumab $(300 \mathrm{mg} /$ $150 \mathrm{mg}$ ) group and etanercept group in the pooled analysis of 10 clinical trials over 52 weeks in 3,993 psoriasis patients (van de Kerkhof et al., 2016). In phase III clinical trials of brodalumab AMAGINE-1, five MACEs occurred, including two in patients treated with placebo and three in patients receiving constant $210 \mathrm{mg}$ of brodalumab (Papp et al., 2016). Moreover, in the AMAGINE-2 and AMAGINE-3 studies, deaths occurred due to cardiovascular problems such as stroke and cardiac arrest (Lebwohl et al., 2015). A study evaluating the long-term safety of ixekizumab from 13 clinical trials reported 84 cases of MACEs among 5,697 psoriasis patients, with no significant increase in the cardiovascular risk or the incidence (Armstrong et al., 2020). Overall, data obtained primarily from pivotal clinical trials of short-term studies on anti-IL-17 therapy in patients with moderate-to-severe psoriasis plaque did not demonstrate an increased risk of CVDs. However, considering the limitations of these data, more long-term studies are necessary to determine the cardiovascular risk.

Prospective CARIMA trials (NCT02559622) that incorporated patients with moderate-to-severe psoriasis with or without severe CVD aimed to evaluate the influence of secukinumab on endothelial dysfunction over 52 weeks, and indicated a protective effect of secukinumab on CVD by improving the endothelial function and flow-mediated dilation in psoriasis patients (von Stebut et al., 2019). Recently prospective studies on the impact of IL-17 inhibitors on cardiovascular risk are ongoing such as Vascular Inflammation in Psoriasis (VIP) trials of secukinumab (VIP-S; NCT02690701), which is evaluating the cardiovascular risk in psoriasis patients from many aspects, including aortic inflammation and cardiometabolic biomarkers.

\section{IL-17 Inhibitors and Obesity}

Inflammation propagation in obese adipose tissues is facilitated by IL-17A without impairing the adipogenesis and insulin response induced by the inflammatory environment (Pestel et al., 2020). In real-life cohorts including a majority of psoriasis patients with cardiometabolic comorbidities, real-world data of the baseline characteristics and clinical response to secukinumab suggested that patients with high BMI and obesity appeared to show a lower persistence of the curative effect and an adverse effect of PASI $\leq 3$ response at week 78 (Rompoti et al., 2020). In contrast to the weightenhancing effects of TNF- $\alpha$ inhibitor treatment, anti-IL-17 therapy as well as anti-IL-12/23 therapy appears to show no increase in body weight and BMI (Wu et al., 2020). Riskbenefit analyses of four RCTs that enrolled 2,403 patients with plaque psoriasis showed that patients with body weight less than $90 \mathrm{~kg}$ treated with $150 \mathrm{mg}$ secukinumab and patients with body weight of $90 \mathrm{~kg}$ or more treated with $300 \mathrm{mg}$ secukinumab had comparable efficacy and safety, suggesting that weight is a pivotal factor to be considered in dosing regimen recommendation (Lee et al., 2019b). However, another IL-17 inhibitor brodalumab showed no significant difference in efficacy and safety between nonobese and obese patients in post-hoc analysis of the AMAGINE-2 and AMAGINE- 3 trials (Hsu et al., 2020). The impact of the IL-17A inhibitor secukinumab on adipose tissue and cutaneous inflammation in patients with moderate-tosevere psoriasis is being explored prospectively in the ongoing ObePso-S trial (NCT03055494) (Korman, 2020).

The findings from studies exploring the effect of biologic therapy on cardiometabolic syndrome in the treatment of psoriasis are summarized in Table $\mathbf{1}$.

\section{Overlapping Mechanisms Between Cardiometabolic Diseases and Psoriasis}

Laboratory research has explored mechanistic links between psoriasis and CVDs related to the inflammatory cascades integrated by activated immune cells and upregulation of proinflammatory cytokines and mediators that influence both psoriasis and atherosclerosis (Flammer and Ruschitzka, 2012). Activation of the innate immune system is considered to be indispensable to initiate the inflammatory cascade in psoriasis, and components of the innate immune system, including neutrophils, dendritic cells, macrophages, and proinflammatory cytokines such as TNF- $\alpha$ and IL-18 have been shown to exist in psoriatic adipose tissue. Deranged lipid distribution and impaired adipose function have been confirmed to accelerate the build-up of atherosclerotic plaques in cardiovascular diseases (Sajja et al., 2018). The critical T-cell differentiation into Th1 and Th17 cells, which is stimulated by IL12 and IL-23 and leads to the release of cytokines such as TNF- $\alpha$, IFN- $\gamma$, IL-17, and IL-22 in the process of adaptive immunity, overlaps between psoriasis and cardiometabolic diseases leading to augmented keratinocyte proliferation and angiogenesis 
TABLE 1 | Effect of biologics on cardiometabolic comorbidities.

\begin{tabular}{|c|c|c|c|c|c|}
\hline \multirow{2}{*}{$\begin{array}{l}\text { Target } \\
\text { therapy }\end{array}$} & \multirow[t]{2}{*}{ Biologics } & \multicolumn{4}{|c|}{ Effect of biologics on } \\
\hline & & Cardiovascular diseases & Obesity & Metabolic syndrome & Diabetes mellitus \\
\hline $\begin{array}{l}\text { TNF- } \alpha \\
\text { inhibitors }\end{array}$ & $\begin{array}{l}\text { Adalimumab } \\
\text { infliximab } \\
\text { certolizumab-pegol } \\
\text { etanercept }\end{array}$ & $\begin{array}{l}\text { Various studies have } \\
\text { demonstrated a reduced } \\
\text { cardiovascular risk Wu and Poon } \\
\text { (2013a), Wu and Poon (2013b), } \\
\text { decreased level of cardiovascular } \\
\text { bio-markers Boehncke et al. } \\
\text { (2011), Sigurdardottir et al. } \\
\text { (2014), and improved arterial } \\
\text { stiffness after treatment Angel } \\
\text { et al. (2010). Controversy exists } \\
\text { in the effect of vascular } \\
\text { inflammation Bissonnette et al. }\end{array}$ & $\begin{array}{l}\text { Observational data indicated } \\
\text { an increase in weight gain after } \\
\text { treatment Saraceno et al. } \\
\text { (2008). A prospective study } \\
\text { indicated a better efficacy and } \\
\text { response of biologics after } \\
\text { weight loss Di Minno et al. } \\
\text { (2014). Infliximab (dosed on } \\
\text { weight) is not affected by } \\
\text { weight Clark and Lebwohl } \\
\text { (2008), Dalamaga and } \\
\text { Papadavid (2019). }\end{array}$ & $\begin{array}{l}\text { A prospective cohort study } \\
\text { reported TNF- } \alpha \text { inhibitors are } \\
\text { beneficial to regulate } \\
\text { metabolic state by } \\
\text { decreasing levels of total } \\
\text { cholesterol and low-density } \\
\text { lipoprotein cholesterol } \\
\text { Botelho et al. (2020), but a } \\
\text { more precise impact needs } \\
\text { further exploration Channual } \\
\text { et al. (2009). }\end{array}$ & $\begin{array}{l}\text { Contradictory results have been } \\
\text { reported that the effect of } \\
\text { etanercept on insulin sensitivity } \\
\text { Marra et al. (2007), } \\
\text { Martínez-Abundis et al. (2007), } \\
\text { Stanley et al. (2011). Adalimumab } \\
\text { improved insulin sensitivity in non- } \\
\text { diabetic patients affected by } \\
\text { psoriasis in a prospective study } \\
\text { Pina et al. (2015). }\end{array}$ \\
\hline
\end{tabular}

\begin{tabular}{|c|c|c|c|c|}
\hline $\begin{array}{l}\text { IL-12/ } \\
23 p 40 \\
\text { inhibitors }\end{array}$ & $\begin{array}{l}\text { Ustekinumab } \\
\text { briakinumab }\end{array}$ & $\begin{array}{l}\text { Briakinumab was withdrawn } \\
\text { from the market due to the } \\
\text { increased cardiovascular risk } \\
\text { Gordon et al. (2012), Langley } \\
\text { et al. (2013). The effect of } \\
\text { ustekinumab on MACEs } \\
\text { demonstrated in several studies } \\
\text { is neither detrimental nor } \\
\text { beneficial Reich et al. (2011), } \\
\text { Ryan et al. (2011). Another } \\
\text { analysis reported a greater } \\
\text { improvement of vascular, } \\
\text { coronary, and myocardial } \\
\text { function after ustekinumab } \\
\text { treatment Ikonomidis et al. } \\
\text { (2017). }\end{array}$ & $\begin{array}{l}\text { Anti-IL-12/23 therapy appears } \\
\text { no increase in body weight } \\
\text { and BMI Wu et al. (2020). }\end{array}$ & $\begin{array}{l}\text { No significant change of mean lipid levels after ustekinumab } \\
\text { treatment for } 1 \text { year at follow-up was observed in a study Hjuler } \\
\text { et al. (2016). And similar results were also found in another study } \\
\text { that body mass index, lipids, or glucose remained unchanged at } \\
\text { 1-year follow-up of psoriasis treated with biologics Elnabawi et al. } \\
\text { (2019b). }\end{array}$ \\
\hline $\begin{array}{l}\text { IL-17 } \\
\text { inhibitors }\end{array}$ & $\begin{array}{l}\text { Ecukinumab } \\
\text { ixekizumab } \\
\text { brodalumab }\end{array}$ & $\begin{array}{l}\text { IL-17 has the double effect of } \\
\text { promoting or preventing } \\
\text { atherosclerotic plaques Taleb } \\
\text { et al. (2015). IL-17 therapy didn't } \\
\text { demonstrate an increased risk of } \\
\text { cardiovascular diseases in a few } \\
\text { short-term studies Wu et al. } \\
\text { (2017b), Rungapiromnan et al. } \\
\text { (2017), Armstrong et al. (2020). } \\
\text { More long-term prospective } \\
\text { studies are ongoing. }\end{array}$ & $\begin{array}{l}\text { IL-17 inhibitors appear no } \\
\text { increase in body weight and } \\
\text { BMI Wu et al. (2020). Weight is } \\
\text { a pivotal factor to influence the } \\
\text { efficacy and response of anti- } \\
\text { IL17 therapy Lee et al. } \\
\text { (2019b), Rompoti et al. (2020). }\end{array}$ & - \\
\hline $\begin{array}{l}\text { IL-23p19 } \\
\text { inhibitors }\end{array}$ & $\begin{array}{l}\text { Guselkumab } \\
\text { tildrakizumab } \\
\text { risankizumab }\end{array}$ & \multicolumn{3}{|c|}{$\begin{array}{l}\text { Current clinical trials are not sufficient to draw conclusion about its impact on cardiometabolic risk of psoriasis patients, only can reflect } \\
\text { the cardiovascular safety in a short term. }\end{array}$} \\
\hline
\end{tabular}

(Lockshin et al., 2018). Another potential mechanism of insulin resistance can be induced by the chronic inflammatory state in psoriatic diseases, and both of them may contribute to the early stage of the formation of atherosclerotic plaques leading to cardiometabolic diseases by causing endothelial dysfunction and increased intima-media thickness in patients with psoriasis (Siegel et al., 2013). Adipokines, a group of proteins secreted by adipocytes, including leptin, visfatin, and resistin, promote the inflammatory condition in psoriasis patients by the correlation with immune cells and pro-inflammatory factors, which in turn results in the appearance of an abnormal serum adipokine profile in patients with psoriasis (Toussirot et al., 2014). Genetic and environmental factors play a role in the comorbidity of psoriasis and metabolic disorders (Lønnberg et al., 2016). For example, the pleiotropic susceptibility loci CDKAL1 contributes to the occurrence of psoriasis as well as diabetes mellitus (Wolf et al., 2008), which may upregulate the inflammatory cytokines in psoriasis promoting insulin resistance, an independent risk factor of T2DM (Gelfand, 2016). One study indicated that psoriatic patients with normal glucose tolerance show insulin resistance or impaired insulin sensitivity, which may further develop into diabetes (Gyldenløve et al., 2015). The inflammatory condition affecting the systemic circulation in psoriasis is regarded as a promoter of components of metabolic syndrome such as insulin resistance, vascular dysfunction, dyslipidemia, and the systemic inflammation also becomes an inducer of endothelial dysfunction, oxidative stress, and increased angiogenesis (Gisondi et al., 2018). Therefore, 


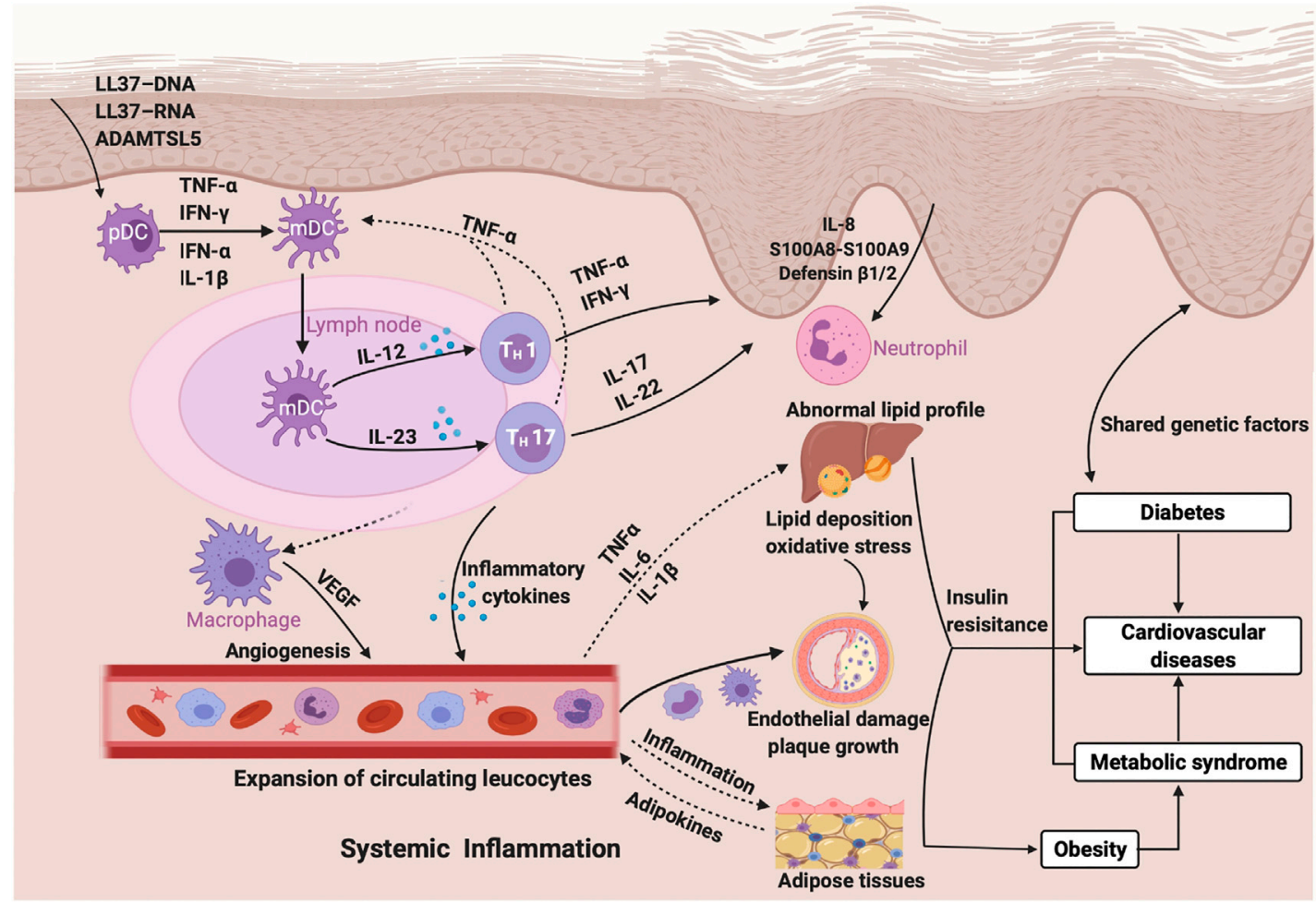

FIGURE 1 | Psoriasis, cardiometabolic comorbidities, and their common inflammatory pathway.

systemic inflammation may be the foremost shared pathophysiology pathways between psoriasis and cardiometabolic diseases, which awaits future exploration (Figure 1).

\section{Suggestions for the Management of Cardiometabolic Diseases in Psoriasis}

Cardiovascular risks in psoriatic patients should be addressed with vigilance, and screening for the traditional cardiovascular risk factors and inflammatory markers such as CRP should be performed to predict the incidence of cardiovascular events (Kimball et al., 2008). Appropriate treatment options should be implemented considering the systemic condition of patients to reduce the risk and severity of cardiovascular disorders (Kristensen et al., 2015). Early determination of the cardiovascular risk in patients with psoriasis is recommended to facilitate effective management and prevent the occurrence of cardiovascular events in psoriatic patients, and precautions against cardiovascular events may also reduce the severity of psoriasis ( $\mathrm{Hu}$ and Lan, 2017). The significance of weight control and monitoring should be emphasized because weight loss can improve the severity of psoriasis in obese patients and decrease the risk of cardiovascular events (Debbaneh et al., 2014). In the majority of studies, weight or BMI was a critical factor that negatively affected the therapeutic response to biologics and disease-modifying anti-rheumatic drugs; therefore, more attention should be paid to weight or BMI control during the treatment (Batalla et al., 2015). Screening the risk of diabetes mellitus in patients with psoriasis and implementation of preventive measures against the occurrence of diabetes mellitus should also receive importance, especially in patients with high affected BSA, since data shows that every $10 \%$ increase in BSA affected by psoriasis is accompanied by a $20 \%$ increase in diabetes risk (Wan et al., 2018). During the treatment of psoriasis, attention should be paid to the relationship between concomitant medications and the hazard of diabetes mellitus to select appropriate drugs for treatment, and blood glucose monitoring of patients should be strengthened (Lee et al., 2014). Given the mutual interaction of psoriasis and metabolic syndrome, preventive management of individual components of metabolic syndrome can also prevent the inflammation infiltrating into the skin to cause psoriasis. On the other hand, the significance of monitoring blood pressure, fasting plasma glucose level, HDL cholesterol, triglyceride level, and waist circumference to determine the development of metabolic syndrome after the diagnosis of psoriasis cannot be ignored. It is worth mentioning that there are certain other comorbidities and concomitant conditions, such as pediatric age group, pregnancy, and concomitant chronic infections, in addition to cardiometabolic comorbidities discussed in this review. All the comorbidities and concomitant conditions should also be considered when selecting optimal treatment 
for psoriasis patients to guarantee its safety and efficacy (Kaushik and Lebwohl, 2019a; Kaushik and Lebwohl, 2019b).

\section{AUTHOR CONTRIBUTIONS}

All authors contributed to the literature search, analysis of the articles and preparation of the manuscript.

\section{FUNDING}

This work was sponsored by grants from National Natural Science Foundation of China (No.487 81673050, 81872522,

\section{REFERENCES}

Abuabara, K., Azfar, R. S., Shin, D. B., Neimann, A. L., Troxel, A. B., and Gelfand, J. M. (2010). Cause-specific Mortality in Patients with Severe Psoriasis: a Population-Based Cohort Study in the U.K. Br. J. Dermatol. 163 (3), 586-592. doi:10.1111/j.1365-2133.2010.09941.x

Ahlehoff, O., Gislason, G. H., Jørgensen, C. H., Lindhardsen, J., Charlot, M., Olesen, J. B., et al. (2012). Psoriasis and Risk of Atrial Fibrillation and Ischaemic Stroke: a Danish Nationwide Cohort Study. Eur. Heart J. 33 (16), 2054-2064. doi:10.1093/eurheartj/ehr285

Ahlehoff, O., Hansen, P. R., Gislason, G. H., Frydland, M., Bryld, L. E., Elming, H., et al. (2016). Myocardial Function and Effects of Biologic Therapy in Patients with Severe Psoriasis: a Prospective Echocardiographic Study. J. Eur. Acad. Dermatol. Venereol. 30 (5), 819-823. doi:10.1111/jdv.13152

Ait-Oufella, H., Libby, P., and Tedgui, A. (2019). Anticytokine Immune Therapy and Atherothrombotic Cardiovascular Risk. Arterioscler Thromb. Vasc. Biol. 39 (8), 1510-1519. doi:10.1161/ATVBAHA.119.311998

Angel, K., Provan, S. A., Gulseth, H. L., Mowinckel, P., Kvien, T. K., and Atar, D. (2010). Tumor Necrosis Factor-Alpha Antagonists Improve Aortic Stiffness in Patients with Inflammatory Arthropathies: a Controlled Study. Hypertension 55 (2), 333-338. doi:10.1161/HYPERTENSIONAHA.109.143982

Armstrong, A., Paul, C., Puig, L., Boehncke, W. H., Freeman, M., Torii, H., et al. (2020). Safety of Ixekizumab Treatment for up to 5 Years in Adult Patients with Moderate-To-Severe Psoriasis: Results from Greater Than 17,000 Patient-Years of Exposure. Dermatol. Ther. (Heidelb) 10 (1), 133-150. doi:10.1007/s13555019-00340-3

Armstrong, A. W., Harskamp, C. T., and Armstrong, E. J. (2013). Psoriasis and Metabolic Syndrome: a Systematic Review and Meta-Analysis of Observational Studies. J. Am. Acad. Dermatol. 68 (4), 654-662. doi:10.1016/j.jaad.2012.08.015

Armstrong, A. W., Voyles, S. V., Armstrong, E. J., Fuller, E. N., and Rutledge, J. C. (2011). Angiogenesis and Oxidative Stress: Common Mechanisms Linking Psoriasis with Atherosclerosis. J. Dermatol. Sci. 63 (1), 1-9. doi:10.1016/ j.jdermsci.2011.04.007

Aune, D., Snekvik, I., Schlesinger, S., Norat, T., Riboli, E., and Vatten, L. J. (2018). Body Mass index, Abdominal Fatness, Weight Gain and the Risk of Psoriasis: a Systematic Review and Dose-Response Meta-Analysis of Prospective Studies. Eur. J. Epidemiol. 33 (12), 1163-1178. doi:10.1007/s10654-018-0366-z

Batalla, A., González-Fernández, D., González-Lara, L., Abalde, T., SalgadoBoquete, L., Queiro-Silva, R., et al. (2015). Cardiovascular Risk Factors Influence Response to Biological Therapies in Psoriasis. J. Am. Acad. Dermatol. 73 (2), 327-329. doi:10.1016/j.jaad.2015.04.041

Bissonnette, R., Harel, F., Krueger, J. G., Guertin, M. C., Chabot-Blanchet, M., Gonzalez, J., et al. (2017). TNF- $\alpha$ Antagonist and Vascular Inflammation in Patients with Psoriasis Vulgaris: A Randomized Placebo-Controlled Study. J. Invest. Dermatol. 137 (8), 1638-1645. doi:10.1016/j.jid.2017.02.977

Bissonnette, R., Tardif, J. C., Harel, F., Pressacco, J., Bolduc, C., and Guertin, M. C. (2013). Effects of the Tumor Necrosis Factor- $\alpha$ Antagonist Adalimumab on Arterial Inflammation Assessed by Positron Emission Tomography in Patients with Psoriasis: Results of a Randomized Controlled Trial. Circ. Cardiovasc. Imaging 6 (1), 83-90. doi:10.1161/CIRCIMAGING.112.975730
82073429), Innovation Program of Shanghai Municipal Education Commission (No. 2019-01-07-00-07-E00046), the Program of Science and Technology Commission of Shanghai Municipality (No. 18140901800), Excellent Subject Leader Program of Shanghai Municipal Commission of Health and Family Planning (No. 2018BR30), Clinical Research Program of Shanghai Hospital Development Center (No. SHDC2020CR1014B, SHDC12018X06) and Program of Shanghai Academic Research Leader (No. 20XD1403300). This work was supported by grants from Department of Dermatology, Shanghai Skin Disease Hospital, Tongji University School of Medicine, Shanghai, China; Institute of Psoriasis, Tongji University School of Medicine, Shanghai, China.

Blauvelt, A., Papp, K. A., Griffiths, C. E., Randazzo, B., Wasfi, Y., Shen, Y. K., et al (2017). Efficacy and Safety of Guselkumab, an Anti-interleukin-23 Monoclonal Antibody, Compared with Adalimumab for the Continuous Treatment of Patients with Moderate to Severe Psoriasis: Results from the Phase III, Double-Blinded, Placebo- and Active Comparator-Controlled VOYAGE 1 Trial. J. Am. Acad. Dermatol. 76 (3), 405-417. doi:10.1016/j.jaad.2016.11.041

Blauvelt, A., Reich, K., Papp, K. A., Kimball, A. B., Gooderham, M., Tyring, S. K., et al. (2018). Safety of Tildrakizumab for Moderate-To-Severe Plaque Psoriasis: Pooled Analysis of Three Randomized Controlled Trials. Br. J. Dermatol. 179 (3), 615-622. doi:10.1111/bjd.16724

Boehncke, S., Salgo, R., Garbaraviciene, J., Beschmann, H., Hardt, K., Diehl, S., et al. (2011). Effective Continuous Systemic Therapy of Severe Plaque-type Psoriasis Is Accompanied by Amelioration of Biomarkers of Cardiovascular Risk: Results of a Prospective Longitudinal Observational Study. J. Eur. Acad. Dermatol. Venereol. 25 (10), 1187-1193. doi:10.1111/j.1468-3083.2010.03947.x

Boehncke, W.-H., and Schön, M. P. (2015). Psoriasis. The Lancet 386 (9997) 983-994. doi:10.1016/s0140-6736(14)61909-7

Botelho, K. P., Pontes, M. A. A., Rodrigues, C. E. M., and Freitas, M. V. C. (2020). Prevalence of Metabolic Syndrome Among Patients with Psoriasis Treated with TNF Inhibitors and the Effects of Anti-TNF Therapy on Their Lipid Profile: A Prospective Cohort Study. Metab. Syndr. Relat. Disord. 18 (3), 154-160. doi:10.1089/met.2019.0092

Boyd, T., and Kavanaugh, A. (2015). Clinical Guidelines: Addressing Comorbidities in Systemic Inflammatory Disorders. Nat. Rev. Rheumatol. 11 (12), 689-691. doi:10.1038/nrrheum.2015.129

Budu-Aggrey, A., Brumpton, B., Tyrrell, J., Watkins, S., Modalsli, E. H., CelisMorales, C., et al. (2019). Evidence of a Causal Relationship between Body Mass index and Psoriasis: A Mendelian Randomization Study. Plos Med. 16 (1), e1002739. doi:10.1371/journal.pmed.1002739

Campanati, A., Diotallevi, F., Martina, E., Paolinelli, M., Radi, G., and Offidani, A. (2020). Safety Update of Etanercept Treatment for Moderate to Severe Plaque Psoriasis. Expert Opin. Drug Saf. 19 (4), 439-448. doi:10.1080/ 14740338.2020.1740204

Channual, J., Wu, J. J., and Dann, F. J. (2009). Effects of Tumor Necrosis FactorAlpha Blockade on Metabolic Syndrome Components in Psoriasis and Psoriatic Arthritis and Additional Lessons Learned from Rheumatoid Arthritis. Dermatol. Ther. 22 (1), 61-73. doi:10.1111/j.1529-8019.2008.01217.x

Chen, S., Crother, T. R., and Arditi, M. (2010). Emerging Role of IL-17 in Atherosclerosis. J. Innate Immun. 2 (4), 325-333. doi:10.1159/000314626

Cheng, X., Yu, X., Ding, Y. J., Fu, Q. Q., Xie, J. J., Tang, T. T., et al. (2008). The Th17/Treg Imbalance in Patients with Acute Coronary Syndrome. Clin. Immunol. 127 (1), 89-97. doi:10.1016/j.clim.2008.01.009

Choi, H., Uceda, D. E., Dey, A. K., Abdelrahman, K. M., Aksentijevich, M., Rodante, J. A., et al. (2020). Treatment of Psoriasis with Biologic Therapy Is Associated with Improvement of Coronary Artery Plaque Lipid-Rich Necrotic Core: Results from a Prospective, Observational Study. Circ. Cardiovasc. Imaging 13 (9), e011199. doi:10.1161/CIRCIMAGING.120.011199

Chung, E. S., Packer, M., Lo, K. H., Fasanmade, A. A., and Willerson, J. T. (2003). Randomized, Double-Blind, Placebo-Controlled, Pilot Trial of Infliximab, a Chimeric Monoclonal Antibody to Tumor Necrosis Factor-Alpha, in Patients with Moderate-To-Severe Heart Failure: Results of the Anti-TNF Therapy 
against Congestive Heart Failure (ATTACH) Trial. Circulation 107 (25), 3133-3140. doi:10.1161/01.CIR.0000077913.60364.D2

Clark, L., and Lebwohl, M. (2008). The Effect of Weight on the Efficacy of Biologic Therapy in Patients with Psoriasis. J. Am. Acad. Dermatol. 58 (3), 443-446. doi:10.1016/j.jaad.2007.11.011

D’Adamio, S., Silvaggio, D., Lombardo, P., Bianchi, L., Talamonti, M., and Galluzzo, M. (2019). The Safety of Anti-interleukins Monoclonal Antibodies for the Treatment of Psoriasis. Expert Opin. Drug Saf. 18 (11), 1031-1041. doi:10.1080/14740338.2019.1663168

Dalamaga, M., and Papadavid, E. (2019). Can We Better Strategize Our Choice of Pharmacotherapy for Patients with Co-morbid Psoriasis and Obesity. Expert Opin. Pharmacother. 20 (11), 1303-1308. doi:10.1080/ 14656566.2019.1603294

Davidovici, B. B., Sattar, N., Prinz, J., Jörg, P. C., Puig, L., Emery, P., et al. (2010). Psoriasis and Systemic Inflammatory Diseases: Potential Mechanistic Links between Skin Disease and Co-morbid Conditions. J. Invest. Dermatol. 130 (7), 1785-1796. doi:10.1038/jid.2010.103

Debbaneh, M., Millsop, J. W., Bhatia, B. K., Koo, J., and Liao, W. (2014). Diet and Psoriasis, Part I: Impact of Weight Loss Interventions. J. Am. Acad. Dermatol. 71 (1), 133-140. doi:10.1016/j.jaad.2014.02.012

Deng, Y., and Scherer, P. E. (2010). Adipokines as Novel Biomarkers and Regulators of the Metabolic Syndrome. Ann. N. Y Acad. Sci. 1212, E1-E19. doi:10.1111/j.1749-6632.2010.05875.x

Dey, A. K., Joshi, A. A., Chaturvedi, A., Lerman, J. B., Aberra, T. M., Rodante, J. A., et al. (2017). Association between Skin and Aortic Vascular Inflammation in Patients with Psoriasis: A Case-Cohort Study Using Positron Emission Tomography/Computed Tomography. JAMA Cardiol. 2 (9), 1013-1018. doi:10.1001/jamacardio.2017.1213

Di Minno, M. N., Peluso, R., Iervolino, S., Russolillo, A., Lupoli, R., and Scarpa, R. (2014). Weight Loss and Achievement of Minimal Disease Activity in Patients with Psoriatic Arthritis Starting Treatment with Tumour Necrosis Factor a Blockers. Ann. Rheum. Dis. 73 (6), 1157-1162. doi:10.1136/annrheumdis-2012202812

Donath, M. Y. (2014). Targeting Inflammation in the Treatment of Type 2 Diabetes: Time to Start. Nat. Rev. Drug Discov. 13 (6), 465-476. doi:10.1038/nrd4275

Eckel, R. H., Alberti, K. G., Grundy, S. M., and Zimmet, P. Z. (2010). The Metabolic Syndrome. Lancet 375 (9710), 181-183. doi:10.1016/S0140-6736(09)61794-3

Egeberg, A., Skov, L., Joshi, A. A., Mallbris, L., Gislason, G. H., Wu, J. J., et al. (2017). The Relationship between Duration of Psoriasis, Vascular Inflammation, and Cardiovascular Events. J. Am. Acad. Dermatol. 77 (4), 650-e3. doi:10.1016/j.jaad.2017.06.028

Eid, R. E., Rao, D. A., Zhou, J., Lo, S. F., Ranjbaran, H., Gallo, A., et al. (2009). Interleukin-17 and Interferon-Gamma Are Produced Concomitantly by Human Coronary Artery-Infiltrating $\mathrm{T}$ Cells and Act Synergistically on Vascular Smooth Muscle Cells. Circulation 119 (10), 1424-1432. doi:10.1161/CIRCULATIONAHA.108.827618

Elnabawi, Y. A., Dey, A. K., Goyal, A., Groenendyk, J. W., Chung, J. H., Belur, A. D., et al. (2019). Coronary Artery Plaque Characteristics and Treatment with Biologic Therapy in Severe Psoriasis: Results from a Prospective Observational Study. Cardiovasc. Res. 115 (4), 721-728. doi:10.1093/cvr/cvz009

Elnabawi, Y. A., Oikonomou, E. K., Dey, A. K., Mancio, J., Rodante, J. A., Aksentijevich, M., et al. (2019). Association of Biologic Therapy with Coronary Inflammation in Patients with Psoriasis as Assessed by Perivascular Fat Attenuation Index. JAMA Cardiol. 4 (9), 885-891. doi:10.1001/jamacardio.2019.2589

Flammer, A. J., and Ruschitzka, F. (2012). Psoriasis and Atherosclerosis: Two Plaques, One Syndrome. Eur. Heart J. 33 (16), 1989-1991. doi:10.1093/ eurheartj/ehr425

Gami, A. S., Witt, B. J., Howard, D. E., Erwin, P. J., Gami, L. A., Somers, V. K., et al. (2007). Metabolic Syndrome and Risk of Incident Cardiovascular Events and Death: a Systematic Review and Meta-Analysis of Longitudinal Studies. J. Am. Coll. Cardiol. 49 (4), 403-414. doi:10.1016/j.jacc.2006.09.032

Gelfand, J. M. (2018). Commentary: Does Biologic Treatment of Psoriasis Lower the Risk of Cardiovascular Events and Mortality?: A Critical Question that We Are Only Just Beginning to Answer. J. Am. Acad. Dermatol. 79 (1), 69-70. doi:10.1016/j.jaad.2018.03.046
Gelfand, J. M., Neimann, A. L., Shin, D. B., Wang, X., Margolis, D. J., and Troxel, A. B. (2006). Risk of Myocardial Infarction in Patients with Psoriasis. JAMA 296 (14), 1735-1741. doi:10.1001/jama.296.14.1735

Gelfand, J. M. (2016). Psoriasis, Type 2 Diabetes Mellitus, and Obesity: Weighing the Evidence. JAMA Dermatol. 152 (7), 753-754. doi:10.1001/ jamadermatol.2016.0670

Gisondi, P., Del Giglio, M., and Girolomoni, G. (2016). Considerations for Systemic Treatment of Psoriasis in Obese Patients. Am. J. Clin. Dermatol. 17 (6), 609-615. doi:10.1007/s40257-016-0211-7

Gisondi, P., Fostini, A. C., Fossà, I., Girolomoni, G., and Targher, G. (2018). Psoriasis and the Metabolic Syndrome. Clin. Dermatol. 36 (1), 21-28. doi:10.1016/j.clindermatol.2017.09.005

Gisterå, A., Robertson, A. K., Andersson, J., Ketelhuth, D. F., Ovchinnikova, O., Nilsson, S. K., et al. (2013). Transforming Growth Factor- $\beta$ Signaling in T Cells Promotes Stabilization of Atherosclerotic Plaques through an Interleukin-17dependent Pathway. Sci. Transl Med. 5 (196), 196ra100. doi:10.1126/ scitranslmed.3006133

Gordon, K. B., Langley, R. G., Gottlieb, A. B., Papp, K. A., Krueger, G. G., Strober, B. E., et al. (2012). A Phase III, Randomized, Controlled Trial of the Fully Human IL-12/23 mAb Briakinumab in Moderate-To-Severe Psoriasis. J. Invest. Dermatol. 132 (2), 304-314. doi:10.1038/jid.2011.304

Gordon, K. B., Strober, B., Lebwohl, M., Augustin, M., Blauvelt, A., Poulin, Y., et al. (2018). Efficacy and Safety of Risankizumab in Moderate-To-Severe Plaque Psoriasis (UltIMMa-1 and UltIMMa-2): Results from Two Double-Blind, Randomised, Placebo-Controlled and Ustekinumab-Controlled Phase 3 Trials. Lancet 392 (10148), 650-661. doi:10.1016/S0140-6736(18)31713-6

Griffiths, C. E., and Barker, J. N. (2007). Pathogenesis and Clinical Features of Psoriasis. Lancet 370 (9583), 263-271. doi:10.1016/S0140-6736(07)61128-3

Griffiths, C. E., Reich, K., Lebwohl, M., van de Kerkhof, P., Paul, C., Menter, A., et al. (2015). Comparison of Ixekizumab with Etanercept or Placebo in Moderate-To-Severe Psoriasis (UNCOVER-2 and UNCOVER-3): Results from Two Phase 3 Randomised Trials. Lancet 386 (9993), 541-551. doi:10.1016/S0140-6736(15)60125-8

Gyldenløve, M., Storgaard, H., Holst, J. J., Vilsbøll, T., Knop, F. K., and Skov, L. (2015). Patients with Psoriasis Are Insulin Resistant. J. Am. Acad. Dermatol. 72 (4), 599-605. doi:10.1016/j.jaad.2015.01.004

Heeschen, C., Dimmeler, S., Hamm, C. W., Boersma, E., Zeiher, A. M., and Simoons, M. L. (2003). Prognostic Significance of Angiogenic Growth Factor Serum Levels in Patients with Acute Coronary Syndromes. Circulation 107 (4), 524-530. doi:10.1161/01.cir.0000048183.37648.1a

Herédi, E., Végh, J., Pogácsás, L., Gáspár, K., Varga, J., Kincse, G., et al. (2016). Subclinical Cardiovascular Disease and It's Improvement after Long-Term TNF- $\alpha$ Inhibitor Therapy in Severe Psoriatic Patients. J. Eur. Acad. Dermatol. Venereol. 30 (9), 1531-1536. doi:10.1111/jdv.13649

Hjuler, K. F., Bøttcher, M., Vestergaard, C., Bøtker, H. E., Iversen, L., and Kragballe, K. (2016). Association between Changes in Coronary Artery Disease Progression and Treatment with Biologic Agents for Severe Psoriasis. JAMA Dermatol. 152 (10), 1114-1121. doi:10.1001/jamadermatol.2016.1984

Hori, M., and Yamaguchi, O. (2013). Is Tumor Necrosis Factor- $\alpha$ Friend or Foe for Chronic Heart Failure. Circ. Res. 113 (5), 492-494. doi:10.1161/ CIRCRESAHA.113.302024

Hsu, S., Green, L. J., Lebwohl, M. G., Wu, J. J., Blauvelt, A., and Jacobson, A. A. (2020). Comparable Efficacy and Safety of Brodalumab in Obese and Nonobese Patients with Psoriasis: Analysis of Two Randomized Controlled Trials. Br. J. Dermatol. 182 (4), 880-888. doi:10.1111/bjd.18327

Hu, S. C., and Lan, C. E. (2017). Psoriasis and Cardiovascular Comorbidities: Focusing on Severe Vascular Events, Cardiovascular Risk Factors and Implications for Treatment. Int. J. Mol. Sci. 18 (10), 2211. doi:10.3390/ ijms 18102211

Ikonomidis, I., Papadavid, E., Makavos, G., Andreadou, I., Varoudi, M., Gravanis, K., et al. (2017). Lowering Interleukin-12 Activity Improves Myocardial and Vascular Function Compared with Tumor Necrosis Factor-A Antagonism or Cyclosporine in Psoriasis. Circ. Cardiovasc. Imaging 10 (9), e006283. doi:10.1161/CIRCIMAGING.117.006283

Jensen, P., Zachariae, C., Christensen, R., Geiker, N. R., Schaadt, B. K., Stender, S., et al. (2013). Effect of Weight Loss on the Severity of Psoriasis: a Randomized Clinical Study. JAMA Dermatol. 149 (7), 795-801. doi:10.1001/ jamadermatol.2013.722 
Johnsson, H., McInnes, I. B., and Sattar, N. (2012). Cardiovascular and Metabolic Risks in Psoriasis and Psoriatic Arthritis: Pragmatic Clinical Management Based on Available Evidence. Ann. Rheum. Dis. 71 (4), 480-483. doi:10.1136/annrheumdis-2011-200567

Jókai, H., Szakonyi, J., Kontár, O., Marschalkó, M., Szalai, K., Kárpáti, S., et al. (2013). Impact of Effective Tumor Necrosis Factor-Alfa Inhibitor Treatment on Arterial Intima-media Thickness in Psoriasis: Results of a Pilot Study. J. Am. Acad. Dermatol. 69 (4), 523-529. doi:10.1016/j.jaad.2013.06.019

Karbach, S., Croxford, A. L., Oelze, M., Schüler, R., Minwegen, D., Wegner, J., et al. (2014). Interleukin 17 Drives Vascular Inflammation, Endothelial Dysfunction, and Arterial Hypertension in Psoriasis-like Skin Disease. Arterioscler Thromb. Vasc. Biol. 34 (12), 2658-2668. doi:10.1161/ATVBAHA.114.304108

Kaushik, S. B., and Lebwohl, M. G. (2019). Psoriasis: Which Therapy for Which Patient: Psoriasis Comorbidities and Preferred Systemic Agents. J. Am. Acad. Dermatol. 80 (1), 27-40. doi:10.1016/j.jaad.2018.06.057

Kaushik, S. B., and Lebwohl, M. G. (2019). Psoriasis: Which Therapy for Which Patient: Focus on Special Populations and Chronic Infections. J. Am. Acad. Dermatol. 80 (1), 43-53. doi:10.1016/j.jaad.2018.06.056

Khalid, U., Ahlehoff, O., Gislason, G. H., Kristensen, S. L., Skov, L., Torp-Pedersen, C., et al. (2014). Psoriasis and Risk of Heart Failure: a Nationwide Cohort Study. Eur. J. Heart Fail. 16 (7), 743-748. doi:10.1002/ejhf.113

Khalid, U., Hansen, P. R., Gislason, G. H., Lindhardsen, J., Kristensen, S. L., Winther, S. A., et al. (2013). Psoriasis and New-Onset Diabetes: a Danish Nationwide Cohort Study. Diabetes care 36 (8), 2402-2407. doi:10.2337/dc122330

Kim, E. S., Han, K., Kim, M. K., Park, Y. M., Baek, K. H., Moon, S. D., et al. (2017). Impact of Metabolic Status on the Incidence of Psoriasis: a Korean Nationwide Cohort Study. Sci. Rep. 7 (1), 1989. doi:10.1038/s41598-017-01983-y

Kim, H. N., Han, K., Park, Y. G., and Lee, J. H. (2019). Metabolic Syndrome Is Associated with an Increased Risk of Psoriasis: A Nationwide Population-Based Study. Metabolism 99, 19-24. doi:10.1016/j.metabol.2019.07.001

Kimball, A. B., Gladman, D., Gelfand, J. M., Gordon, K., Horn, E. J., Korman, N. J., et al. (2008). National Psoriasis Foundation Clinical Consensus on Psoriasis Comorbidities and Recommendations for Screening. J. Am. Acad. Dermatol. 58 (6), 1031-1042. doi:10.1016/j.jaad.2008.01.006

Kimball, A. B., Papp, K. A., Wasfi, Y., Chan, D., Bissonnette, R., Sofen, H., et al. (2013). Long-term Efficacy of Ustekinumab in Patients with Moderate-ToSevere Psoriasis Treated for up to 5 Years in the PHOENIX 1 Study. J. Eur. Acad. Dermatol. Venereol. 27 (12), 1535-1545. doi:10.1111/jdv.12046

Knowles, L., Nadeem, N., and Chowienczyk, P. J. (2020). Do anti-tumour Necrosis Factor- $\alpha$ Biologics Affect Subclinical Measures of Atherosclerosis and Arteriosclerosis? A Systematic Review. Br. J. Clin. Pharmacol. 86 (5), 837-851. doi:10.1111/bcp.14215

Korman, N. J. (2020). Management of Psoriasis as a Systemic Disease: what Is the Evidence. Br. J. Dermatol. 182 (4), 840-848. doi:10.1111/bjd.18245

Kristensen, S. L., McInnes, I. B., and Sattar, N. (2015). Psoriasis, Psoriatic Arthritis and Cardiovascular Risk: Are We Closer to a Clinical Recommendation. Ann. Rheum. Dis. 74 (2), 321-322. doi:10.1136/ annrheumdis-2014-206617

Langley, R. G., Elewski, B. E., Lebwohl, M., Reich, K., Griffiths, C. E., Papp, K., et al. (2014). Secukinumab in Plaque Psoriasis-Rresults of Two Phase 3 Trials. $N$. Engl. J. Med. 371 (4), 326-338. doi:10.1056/NEJMoa1314258

Langley, R. G., Papp, K., Gottlieb, A. B., Krueger, G. G., Gordon, K. B., Williams, D., et al. (2013). Safety Results from a Pooled Analysis of Randomized, Controlled Phase II and III Clinical Trials and Interim Data from an Open-Label Extension Trial of the Interleukin-12/23 Monoclonal Antibody, Briakinumab, in Moderate to Severe Psoriasis. J. Eur. Acad. Dermatol. Venereol. 27 (10), 1252-1261. doi:10.1111/j.1468-3083.2012.04705.x

Langley, R. G., Tsai, T. F., Flavin, S., Song, M., Randazzo, B., Wasfi, Y., et al. (2018). Efficacy and Safety of Guselkumab in Patients with Psoriasis Who Have an Inadequate Response to Ustekinumab: Results of the Randomized, DoubleBlind, Phase III Navigate Trial. Br. J. Dermatol. 178 (1), 114-123. doi:10.1111/ bjd. 15750

Lebwohl, M., Strober, B., Menter, A., Gordon, K., Weglowska, J., Puig, L., et al. (2015). Phase 3 Studies Comparing Brodalumab with Ustekinumab in Psoriasis. N. Engl. J. Med. 373 (14), 1318-1328. doi:10.1056/NEJMoa1503824

Lee, J. E., Wang, J., Florian, J., Wang, Y. M., Kettl, D., Marcus, K., et al. (2019). Effect of Body Weight on Risk-Benefit and Dosing Regimen Recommendation of Secukinumab for the Treatment of Moderate to Severe Plaque Psoriasis. Clin. Pharmacol. Ther. 106 (1), 78-80. doi:10.1002/cpt.1478

Lee, M. P., Desai, R. J., Jin, Y., Brill, G., Ogdie, A., and Kim, S. C. (2019). Association of Ustekinumab vs TNF Inhibitor Therapy with Risk of Atrial Fibrillation and Cardiovascular Events in Patients with Psoriasis or Psoriatic Arthritis. JAMA Dermatol. 155 (6), 700-707. doi:10.1001/jamadermatol.2019.0001

Lee, M. S., Lin, R. Y., and Lai, M. S. (2014). Increased Risk of Diabetes Mellitus in Relation to the Severity of Psoriasis, Concomitant Medication, and Comorbidity: a Nationwide Population-Based Cohort Study. J. Am. Acad. Dermatol. 70 (4), 691-698. doi:10.1016/j.jaad.2013.11.023

Lockshin, B., Balagula, Y., and Merola, J. F. (2018). Interleukin 17, Inflammation, and Cardiovascular Risk in Patients with Psoriasis. J. Am. Acad. Dermatol. 79 (2), 345-352. doi:10.1016/j.jaad.2018.02.040

Lønnberg, A. S., Skov, L., Skytthe, A., Kyvik, K. O., Pedersen, O. B., and Thomsen, S. F. (2016). Association of Psoriasis with the Risk for Type 2 Diabetes Mellitus and Obesity. JAMA Dermatol. 152 (7), 761-767. doi:10.1001/ jamadermatol.2015.6262

Lu, Y., Chen, H., Nikamo, P., Qi Low, H., Helms, C., Seielstad, M., et al. (2013). Association of Cardiovascular and Metabolic Disease Genes with Psoriasis. J. Invest. Dermatol. 133 (3), 836-839. doi:10.1038/jid.2012.366

Mahil, S. K., Capon, F., and Barker, J. N. (2016). Update on Psoriasis Immunopathogenesis and Targeted Immunotherapy. Semin. Immunopathol 38 (1), 11-27. doi:10.1007/s00281-015-0539-8

Malecic, N., and Young, H. S. (2017). Excessive Angiogenesis Associated with Psoriasis as a Cause for Cardiovascular Ischaemia. Exp. Dermatol. 26 (4), 299-304. doi:10.1111/exd.13310

Mallbris, L., Granath, F., Hamsten, A., and Ståhle, M. (2006). Psoriasis Is Associated with Lipid Abnormalities at the Onset of Skin Disease. J. Am. Acad. Dermatol. 54 (4), 614-621. doi:10.1016/j.jaad.2005.11.1079

Mann, D. L., McMurray, J. J., Packer, M., Swedberg, K., Borer, J. S., Colucci, W. S., et al. (2004). Targeted Anticytokine Therapy in Patients with Chronic Heart Failure: Results of the Randomized Etanercept Worldwide Evaluation (RENEWAL). Circulation 109 (13), 1594-1602. doi:10.1161/ 01.CIR.0000124490.27666.B2

Marra, M., Campanati, A., Testa, R., Sirolla, C., Bonfigli, A. R., Franceschi, C., et al. (2007). Effect of Etanercept on Insulin Sensitivity in Nine Patients with Psoriasis. Int. J. Immunopathol Pharmacol. 20 (4), 731-736. doi:10.1177/ 039463200702000408

Martínez-Abundis, E., Reynoso-von Drateln, C., Hernández-Salazar, E., and González-Ortiz, M. (2007). Effect of Etanercept on Insulin Secretion and Insulin Sensitivity in a Randomized Trial with Psoriatic Patients at Risk for Developing Type 2 Diabetes Mellitus. Arch. Dermatol. Res. 299 (9), 461-465. doi:10.1007/s00403-007-0784-3

McKellar, G. E., McCarey, D. W., Sattar, N., and McInnes, I. B. (2009). Role for TNF in Atherosclerosis? Lessons from Autoimmune Disease. Nat. Rev. Cardiol. 6 (6), 410-417. doi:10.1038/nrcardio.2009.57

Mehta, N. N., Azfar, R. S., Shin, D. B., Neimann, A. L., Troxel, A. B., and Gelfand, J. M. (2010). Patients with Severe Psoriasis Are at Increased Risk of Cardiovascular Mortality: Cohort Study Using the General Practice Research Database. Eur. Heart J. 31 (8), 1000-1006. doi:10.1093/eurheartj/ehp567

Melander, O., Newton-Cheh, C., Almgren, P., Hedblad, B., Berglund, G., Engström, G., et al. (2009). Novel and Conventional Biomarkers for Prediction of Incident Cardiovascular Events in the Community. JAMA 302 (1), 49-57. doi:10.1001/ jama.2009.943

Menter, A., Gottlieb, A., Feldman, S. R., Van Voorhees, A. S., Leonardi, C. L, Gordon, K. B., et al. (2008). Guidelines of Care for the Management of Psoriasis and Psoriatic Arthritis: Section 1. Overview of Psoriasis and Guidelines of Care for the Treatment of Psoriasis with Biologics. J. Am. Acad. Dermatol. 58 (5), 826-850. doi:10.1016/j.jaad.2008.02.039

Miller, I. M., Ellervik, C., Yazdanyar, S., and Jemec, G. B. (2013). Meta-analysis of Psoriasis, Cardiovascular Disease, and Associated Risk Factors. J. Am. Acad. Dermatol. 69 (6), 1014-1024. doi:10.1016/j.jaad.2013.06.053

Neimann, A. L., Shin, D. B., Wang, X., Margolis, D. J., Troxel, A. B., and Gelfand, J. M. (2006). Prevalence of Cardiovascular Risk Factors in Patients with Psoriasis. J. Am. Acad. Dermatol. 55 (5), 829-835. doi:10.1016/ j.jaad.2006.08.040

Paller, A. S., Mercy, K., Kwasny, M. J., Choon, S. E., Cordoro, K. M., Girolomoni, G., et al. (2013). Association of Pediatric Psoriasis Severity with Excess and 
central Adiposity: an International Cross-Sectional Study. JAMA Dermatol. 149 (2), 166-176. doi:10.1001/jamadermatol.2013.1078

Papp, K. A., Blauvelt, A., Bukhalo, M., Gooderham, M., Krueger, J. G., Lacour, J. P., et al. (2017). Risankizumab versus Ustekinumab for Moderate-To-Severe Plaque Psoriasis. N. Engl. J. Med. 376 (16), 1551-1560. doi:10.1056/ NEJMoa 1607017

Papp, K. A., Reich, K., Paul, C., Blauvelt, A., Baran, W., Bolduc, C., et al. (2016). A Prospective Phase III, Randomized, Double-Blind, Placebo-Controlled Study of Brodalumab in Patients with Moderate-To-Severe Plaque Psoriasis. $\mathrm{Br}$. J. Dermatol. 175 (2), 273-286. doi:10.1111/bjd.14493

Papp, K. A., Tyring, S., Lahfa, M., Prinz, J., Griffiths, C. E., Nakanishi, A. M., et al. (2005). A Global Phase III Randomized Controlled Trial of Etanercept in Psoriasis: Safety, Efficacy, and Effect of Dose Reduction. Br. J. Dermatol. 152 (6), 1304-1312. doi:10.1111/j.1365-2133.2005.06688.x

Parodi, A., Aste, N., Calvieri, C., Cantoresi, F., Carlesimo, M., Fabbri, P., et al. (2014). Metabolic Syndrome Prevalence in Psoriasis: a Cross-Sectional Study in the Italian Population. Am. J. Clin. Dermatol. 15 (4), 371-377. doi:10.1007/ s40257-014-0074-8

Pestel, J., Chehimi, M., Bonhomme, M., Robert, M., Vidal, H., and Eljaafari, A. (2020). IL-17A Contributes to Propagation of Inflammation but Does Not Impair Adipogenesis And/or Insulin Response, in Adipose Tissue of Obese Individuals. Cytokine 126, 154865. doi:10.1016/j.cyto.2019.154865

Piaserico, S., Osto, E., Famoso, G., Zanetti, I., Gregori, D., Poretto, A., et al. (2016). Treatment with Tumor Necrosis Factor Inhibitors Restores Coronary Microvascular Function in Young Patients with Severe Psoriasis. Atherosclerosis 251, 25-30. doi:10.1016/j.atherosclerosis.2016.05.036

Pina, T., Armesto, S., Lopez-Mejias, R., Genre, F., Ubilla, B., Gonzalez-Lopez, M. A., et al. (2015). Anti-TNF- $\alpha$ Therapy Improves Insulin Sensitivity in Nondiabetic Patients with Psoriasis: a 6-month Prospective Study. J. Eur. Acad. Dermatol. Venereol. 29 (7), 1325-1330. doi:10.1111/jdv.12814

Poizeau, F., Nowak, E., Kerbrat, S., Le Nautout, B., Droitcourt, C., Drici, M. D., et al. (2020). Association between Early Severe Cardiovascular Events and the Initiation of Treatment with the Anti-interleukin 12/23p40 Antibody Ustekinumab. JAMA Dermatol. 156 (11), 1208-1215. doi:10.1001/ jamadermatol.2020.2977

Reich, K., Armstrong, A. W., Foley, P., Song, M., Wasfi, Y., Randazzo, B., et al. (2017). Efficacy and Safety of Guselkumab, an Anti-interleukin-23 Monoclonal Antibody, Compared with Adalimumab for the Treatment of Patients with Moderate to Severe Psoriasis with Randomized Withdrawal and Retreatment: Results from the Phase III, Double-Blind, Placebo- and Active ComparatorControlled VOYAGE 2 Trial. J. Am. Acad. Dermatol. 76 (3), 418-431. doi:10.1016/j.jaad.2016.11.042

Reich, K., Langley, R. G., Lebwohl, M., Szapary, P., Guzzo, C., Yeilding, N., et al. (2011). Cardiovascular Safety of Ustekinumab in Patients with Moderate to Severe Psoriasis: Results of Integrated Analyses of Data from Phase II and III Clinical Studies. Br. J. Dermatol. 164 (4), 862-872. doi:10.1111/j.13652133.2011.10257.x

Reich, K., Nestle, F. O., Papp, K., Ortonne, J. P., Evans, R., Guzzo, C., et al. (2005). Infliximab Induction and Maintenance Therapy for Moderate-To-Severe Psoriasis: a Phase III, Multicentre, Double-Blind Trial. Lancet 366 (9494), 1367-1374. doi:10.1016/S0140-6736(05)67566-6

Ridker, P. M., Cushman, M., Stampfer, M. J., Tracy, R. P., and Hennekens, C. H. (1997). Inflammation, Aspirin, and the Risk of Cardiovascular Disease in Apparently Healthy Men. N. Engl. J. Med. 336 (14), 973-979. doi:10.1056/ NEJM199704033361401

Ridker, P. M. (2010). Psoriasis, Inflammation, and Vascular Risk: a Problem More Than Skin Deep. Eur. Heart J. 31 (8), 902-904. doi:10.1093/eurheartj/ehq042

Robati, R. M., Partovi-Kia, M., Haghighatkhah, H. R., Younespour, S., and Abdollahimajd, F. (2014). Increased Serum Leptin and Resistin Levels and Increased Carotid Intima-media wall Thickness in Patients with Psoriasis: Is Psoriasis Associated with Atherosclerosis. J. Am. Acad. Dermatol. 71 (4), 642-648. doi:10.1016/j.jaad.2014.06.006

Rodríguez-Zúñiga, M. J. M., and García-Perdomo, H. A. (2017). Systematic Review and Meta-Analysis of the Association between Psoriasis and Metabolic Syndrome. J. Am. Acad. Dermatol. 77 (4), 657-e8. doi:10.1016/ j.jaad.2017.04.1133

Rompoti, N., Sidiropoulou, P., Panagakis, P., Stratigos, A., Papoutsaki, M., Stefanaki, E., et al. (2020). Real-world Data from a Single Greek centre on the Use of Secukinumab in Plaque Psoriasis: Effectiveness, Safety, Drug Survival, and Identification of Patients that Sustain Optimal Response. J. Eur. Acad. Dermatol. Venereol. 34 (6), 1240-1247. doi:10.1111/jdv.16202

Rønholt, K., and Iversen, L. (2017). Old and New Biological Therapies for Psoriasis. Int. J. Mol. Sci. 18 (11), 2297. doi:10.3390/ijms18112297

Roubille, C., Richer, V., Starnino, T., McCourt, C., McFarlane, A., Fleming, P., et al. (2015). The Effects of Tumour Necrosis Factor Inhibitors, Methotrexate, Nonsteroidal Anti-inflammatory Drugs and Corticosteroids on Cardiovascular Events in Rheumatoid Arthritis, Psoriasis and Psoriatic Arthritis: a Systematic Review and Meta-Analysis. Ann. Rheum. Dis. 74 (3), 480-489. doi:10.1136/annrheumdis-2014-206624

Rungapiromnan, W., Yiu, Z. Z. N., Warren, R. B., Griffiths, C. E. M., and Ashcroft, D. M. (2017). Impact of Biologic Therapies on Risk of Major Adverse Cardiovascular Events in Patients with Psoriasis: Systematic Review and Meta-Analysis of Randomized Controlled Trials. Br. J. Dermatol. 176 (4), 890-901. doi:10.1111/bjd.14964

Ryan, C., Leonardi, C. L., Krueger, J. G., Kimball, A. B., Strober, B. E., Gordon, K. B., et al. (2011). Association between Biologic Therapies for Chronic Plaque Psoriasis and Cardiovascular Events: a Meta-Analysis of Randomized Controlled Trials. JAMA 306 (8), 864-871. doi:10.1001/jama.2011.1211

Sajja, A. P., Joshi, A. A., Teague, H. L., Dey, A. K., and Mehta, N. N. (2018). Potential Immunological Links between Psoriasis and Cardiovascular Disease. Front. Immunol. 9, 1234. doi:10.3389/fimmu.2018.01234

Salahuddin, T., Natarajan, B., Playford, M. P., Joshi, A. A., Teague, H., Masmoudi, Y., et al. (2015). Cholesterol Efflux Capacity in Humans with Psoriasis Is Inversely Related to Non-calcified burden of Coronary Atherosclerosis. Eur. Heart J. 36 (39), 2662-2665. doi:10.1093/eurheartj/ehv339

Saraceno, R., Schipani, C., Mazzotta, A., Esposito, M., Di Renzo, L., De Lorenzo, A., et al. (2008). Effect of Anti-tumor Necrosis Factor-Alpha Therapies on Body Mass index in Patients with Psoriasis. Pharmacol. Res. 57 (4), 290-295. doi:10.1016/j.phrs.2008.02.006

Saurat, J. H., Stingl, G., Dubertret, L., Papp, K., Langley, R. G., Ortonne, J. P., et al. (2008). Efficacy and Safety Results from the Randomized Controlled Comparative Study of Adalimumab vs. Methotrexate vs. Placebo in Patients with Psoriasis (CHAMPION). Br. J. Dermatol. 158 (3), 558-566. doi:10.1111/ j.1365-2133.2007.08315.x

Sbidian, E., Chaimani, A., Garcia-Doval, I., Do, G., Hua, C., Mazaud, C., et al. (2017). Systemic Pharmacological Treatments for Chronic Plaque Psoriasis: a Network Meta-Analysis. Cochrane Database Syst. Rev. 12, CD011535. doi:10.1002/14651858.CD011535.pub2

Shapiro, J., Cohen, A. D., Weitzman, D., Tal, R., and David, M. (2012). Psoriasis and Cardiovascular Risk Factors: a Case-Control Study on Inpatients Comparing Psoriasis to Dermatitis. J. Am. Acad. Dermatol. 66 (2), 252-258. doi:10.1016/j.jaad.2010.11.046

Shelling, M. L., and Kirsner, R. S. (2013). Practice Gaps. Gaining Insights into the Relationship of Obesity, Weight Loss, and Psoriasis. JAMA Dermatol. 149 (7), 801-802. doi:10.1001/jamadermatol.2013.3383

Siegel, D., Devaraj, S., Mitra, A., Raychaudhuri, S. P., Raychaudhuri, S. K., and Jialal, I. (2013). Inflammation, Atherosclerosis, and Psoriasis. Clin. Rev. Allergy Immunol. 44 (2), 194-204. doi:10.1007/s12016-012-8308-0

Sigurdardottir, G., Ekman, A. K., Ståhle, M., Bivik, C., and Enerbäck, C. (2014). Systemic Treatment and Narrowband Ultraviolet B Differentially Affect Cardiovascular Risk Markers in Psoriasis. J. Am. Acad. Dermatol. 70 (6), 1067-1075. doi:10.1016/j.jaad.2013.12.044

Simon, T., Taleb, S., Danchin, N., Laurans, L., Rousseau, B., Cattan, S., et al. (2013). Circulating Levels of Interleukin-17 and Cardiovascular Outcomes in Patients with Acute Myocardial Infarction. Eur. Heart J. 34 (8), 570-577. doi:10.1093/ eurheartj/ehs 263

Snekvik, I., Nilsen, T. I. L., Romundstad, P. R., and Saunes, M. (2019). Metabolic Syndrome and Risk of Incident Psoriasis: Prospective Data from the HUNT Study, Norway. Br. J. Dermatol. 180 (1), 94-99. doi:10.1111/bjd.16885

Solomon, D. H., Massarotti, E., Garg, R., Liu, J., Canning, C., and Schneeweiss, S. (2011). Association between Disease-Modifying Antirheumatic Drugs and Diabetes Risk in Patients with Rheumatoid Arthritis and Psoriasis. JAMA 305 (24), 2525-2531. doi:10.1001/jama.2011.878

Stanley, T. L., Zanni, M. V., Johnsen, S., Rasheed, S., Makimura, H., Lee, H., et al. (2011). TNF-alpha Antagonism with Etanercept Decreases Glucose and Increases the Proportion of High Molecular Weight Adiponectin in Obese 
Subjects with Features of the Metabolic Syndrome. J. Clin. Endocrinol. Metab. 96 (1), E146-E150. doi:10.1210/jc.2010-1170

Stern, R. S. (2010). Psoriasis Is Not a Useful Independent Risk Factor for Cardiovascular Disease. J. Invest. Dermatol. 130 (4), 917-919. doi:10.1038/ jid.2009.446

Taleb, S., Romain, M., Ramkhelawon, B., Uyttenhove, C., Pasterkamp, G., Herbin, O., et al. (2009). Loss of SOCS3 Expression in T Cells Reveals a Regulatory Role for Interleukin-17 in Atherosclerosis. J. Exp. Med. 206 (10), 2067-2077. doi:10.1084/jem.20090545

Taleb, S., Tedgui, A., and Mallat, Z. (2015). IL-17 and Th17 Cells in Atherosclerosis: Subtle and Contextual Roles. Arterioscler Thromb. Vasc. Biol. 35 (2), 258-264. doi:10.1161/ATVBAHA.114.303567

Toussirot, Ã. r., Aubin, F. o., and Dumoulin, G. (2014). Relationships between Adipose Tissue and Psoriasis, with or without Arthritis. Front. Immunol. 5, 368. doi:10.3389/fimmu.2014.00368

Tzellos, T., Kyrgidis, A., and Zouboulis, C. C. (2013). Re-evaluation of the Risk for Major Adverse Cardiovascular Events in Patients Treated with anti-IL-12/23 Biological Agents for Chronic Plaque Psoriasis: a Meta-Analysis of Randomized Controlled Trials. J. Eur. Acad. Dermatol. Venereol. 27 (5), 622-627. doi:10.1111/j.1468-3083.2012.04500.x

van de Kerkhof, P. C., Griffiths, C. E., Reich, K., Leonardi, C. L., Blauvelt, A., Tsai, T. F., et al. (2016). Secukinumab Long-Term Safety Experience: A Pooled Analysis of 10 Phase II and III Clinical Studies in Patients with Moderate to Severe Plaque Psoriasis. J. Am. Acad. Dermatol. 75 (1), 83-e4. doi:10.1016/ j.jaad.2016.03.024

von Stebut, E., Reich, K., Thaçi, D., Koenig, W., Pinter, A., Körber, A., et al. (2019). Impact of Secukinumab on Endothelial Dysfunction and Other Cardiovascular Disease Parameters in Psoriasis Patients over 52 Weeks. J. Invest. Dermatol. 139 (5), 1054-1062. doi:10.1016/j.jid.2018.10.042

Wan, M. T., Shin, D. B., Hubbard, R. A., Noe, M. H., Mehta, N. N., and Gelfand, J. M. (2018). Psoriasis and the Risk of Diabetes: A Prospective Population-Based Cohort Study. J. Am. Acad. Dermatol. 78 (2), 315-e1. doi:10.1016/ j.jaad.2017.10.050

Wolf, N., Quaranta, M., Prescott, N. J., Allen, M., Smith, R., Burden, A. D., et al. (2008). Psoriasis Is Associated with Pleiotropic Susceptibility Loci Identified in Type II Diabetes and Crohn Disease. J. Med. Genet. 45 (2), 114-116. doi:10.1136/jmg.2007.053595

Wu, C. Y., Shieh, J. J., Shen, J. L., Liu, Y. Y., Chang, Y. T., and Chen, Y. J. (2015). Association between Antidiabetic Drugs and Psoriasis Risk in Diabetic Patients: Results from a Nationwide Nested Case-Control Study in Taiwan. J. Am. Acad. Dermatol. 72 (1), 123-130. doi:10.1016/j.jaad.2014.08.042

Wu, D., Hou, S. Y., Zhao, S., Hou, L. X., Jiao, T., Xu, N. N., et al. (2017). Efficacy and Safety of Interleukin-17 Antagonists in Patients with Plaque Psoriasis: a MetaAnalysis from Phase 3 Randomized Controlled Trials. J. Eur. Acad. Dermatol. Venereol. 31 (6), 992-1003. doi:10.1111/jdv.14125

Wu, J. J., Guérin, A., Sundaram, M., Dea, K., Cloutier, M., and Mulani, P. (2017). Cardiovascular Event Risk Assessment in Psoriasis Patients Treated with Tumor Necrosis Factor- $\alpha$ Inhibitors versus Methotrexate. J. Am. Acad. Dermatol. 76 (1), 81-90. doi:10.1016/j.jaad.2016.07.042
Wu, J. J., and Poon, K. Y. (2013). Association of Ethnicity, Tumor Necrosis Factor Inhibitor Therapy, and Myocardial Infarction Risk in Patients with Psoriasis. J. Am. Acad. Dermatol. 69 (1), 167-168. doi:10.1016/j.jaad.2013.02.019

Wu, J. J., and Poon, K. Y. (2013). Association of Gender, Tumor Necrosis Factor Inhibitor Therapy, and Myocardial Infarction Risk in Patients with Psoriasis. J. Am. Acad. Dermatol. 69 (4), 650-651. doi:10.1016/j.jaad.2013.04.035

Wu, J. J., Sundaram, M., Cloutier, M., Gauthier-Loiselle, M., Guérin, A., Singh, R., et al. (2018). The Risk of Cardiovascular Events in Psoriasis Patients Treated with Tumor Necrosis Factor- $\alpha$ Inhibitors versus Phototherapy: An Observational Cohort Study. J. Am. Acad. Dermatol. 79 (1), 60-68. doi:10.1016/j.jaad.2018.02.050

Wu, M. Y., Yu, C. L., Yang, S. J., and Chi, C. C. (2020). Change in Body Weight and Body Mass index in Psoriasis Patients Receiving Biologics: A Systematic Review and Network Meta-Analysis. J. Am. Acad. Dermatol. 82 (1), 101-109. doi:10.1016/j.jaad.2019.07.103

Wu, S., Han, J., Li, W. Q., and Qureshi, A. A. (2014). Hypertension, Antihypertensive Medication Use, and Risk of Psoriasis. JAMA Dermatol. 150 (9), 957-963. doi:10.1001/jamadermatol.2013.9957

Yang, Z. S., Lin, N. N., Li, L., and Li, Y. (2016). The Effect of TNF Inhibitors on Cardiovascular Events in Psoriasis and Psoriatic Arthritis: an Updated MetaAnalysis. Clin. Rev. Allergy Immunol. 51 (2), 240-247. doi:10.1007/s12016-0168560-9

Yeung, H., Takeshita, J., Mehta, N. N., Kimmel, S. E., Ogdie, A., Margolis, D. J., et al. (2013). Psoriasis Severity and the Prevalence of Major Medical Comorbidity: a Population-Based Study. JAMA Dermatol. 149 (10), 1173-1179. doi:10.1001/jamadermatol.2013.5015

Zhu, Y., Hu, C., Lu, M., Liao, S., Marini, J. C., Yohrling, J., et al. (2009). Population Pharmacokinetic Modeling of Ustekinumab, a Human Monoclonal Antibody Targeting IL-12/23p40, in Patients with Moderate to Severe Plaque Psoriasis. J. Clin. Pharmacol. 49 (2), 162-175. doi:10.1177/0091270008329556

Conflict of Interest: The authors declare that the research was conducted in the absence of any commercial or financial relationships that could be construed as a potential conflict of interest.

Publisher's Note: All claims expressed in this article are solely those of the authors and do not necessarily represent those of their affiliated organizations, or those of the publisher, the editors and the reviewers. Any product that may be evaluated in this article, or claim that may be made by its manufacturer, is not guaranteed or endorsed by the publisher.

Copyright $\odot 2021$ Cai, Cui, Wang, Li, Zhang and Shi. This is an open-access article distributed under the terms of the Creative Commons Attribution License (CC BY). The use, distribution or reproduction in other forums is permitted, provided the original author(s) and the copyright owner(s) are credited and that the original publication in this journal is cited, in accordance with accepted academic practice. No use, distribution or reproduction is permitted which does not comply with these terms. 